\title{
SYNTHESIS OF CHEMICAL ELEMENTS UNDER IRRADIATION BY BRAKING GAMMA-RAYS OF PALLADIUM IN CONDENSED GASES
}

\author{
Alexander Yu. Didyk, Gennady V. Mishinsky, Vasily A. Semin \\ Joint Institute for Nuclear Research, http://www.jinr.ru/ \\ 6, str. Joliot Curie, Dubna 141980, Moscow Region, Russian Federation
}

Roland Wiśniewski, Teresa Wilczyńska-Kitowska

National Centre for Nuclear Research, https://www.ncbj.gov.pl/

ul. Andrzeja Sołtana 7, 05-400 Otwock, Świerk, Poland

roland.wisniewski@gmail.com, teresa.wilczynska@gmail.com,mysh@jinr.ru,seminva@jinr.ru

Abstract. The article is a review of the experimental results obtained by the authors over the past 8 years on the synthesis of chemical elements in gases compressed up to $3 \mathrm{kbar}$ with its long (up to tens of hours) gamma irradiation in the presence of cylindrical samples of metallic palladium. The chambers were irradiated by braking gamma rays with a maximum energy of $10 \mathrm{MeV}$ at the electron accelerator of the Joint Institute for Nuclear Research in Dubna (Moscow region). In addition to palladium, the reaction chamber contained other structural details made of brass or copper, beryllium bronze and manganin foil. Experiments were carried out with palladium in deuterium, with palladium and tin in hydrogen, with palladium in helium. In all experiments, after irradiation, numerous solid-state microstructures of various sizes (up to $1 \mathrm{~mm}$ ) and shapes were found on the surfaces of the chamber's parts, as well as on the surface of the palladium. $\mathrm{X}$-ray micro-probe analysis of these structures showed the presence of a wide range of chemical elements (from carbon to lead), which were absent in the reaction chamber prior to irradiating. The article presents numerous quantitative histograms of concentrations of the elements found. Preliminary hypotheses are proposed for the synthesis of chemical elements under the experimental conditions.

Keywords: condensed gas, high-pressure chambers, gamma radiation, surface microstructures, X-ray analysis, photonuclear reactions, low-energy nuclear reactions, cold nuclear fusion

PACS: 25.20.-x; 25.70.-z; 25.70.Jj

Bibliography - 45 references

Received 24.05.2019, accepted 30.05.2019

RENSIT, 2019, 11(2):143-160

DOI: $10.17725 /$ rensit.2019.11.143

\section{Contents}

1. INTRODUCTION (143)

2. ReCEIVING BRAKING GaMMA RADIATION (145)

3. THE METHODS OF THE EXPERIMENTS (146)

4. The experiments with palladium in DEUTERIUM (147)

5. The experiments with palladium and tin IN HYDROGEN (150)

6. The experiment with palladium in helium (153)

7. Discussion OF THE EXPERIMENTAL RESUlTS (154)

8. Conclusion (157)

REFERENCES (157)

\section{INTRODUCTION}

The phenomenon of synthesis of chemical elements and solid-state structures in a medium of condensed gases under the action of gamma quanta was discovered by A.Yu.Didyk and R.Wiśniewski. The first experiment was carried out in 2011 with a palladium sample $(\mathrm{Pd})$ in the form of a cylinder placed in a chamber with a deuterium pressure of 3 kbar [1-3]. At pressures of 0.5-3 kbar, the density of gas atoms is comparable with the density of atoms in the solid and liquids. Therefore, the term condensed gas is used. Irradiation by braking gamma-quanta was carried out during 6 hours at the MT-25 microtron [4] 
with an electron energy of $9.3 \mathrm{MeV}$ and an average electron current of $7 \mu \mathrm{A}\left(\sim 4.4 \cdot 10^{13} \mathrm{~s}^{-1}\right)$.

The motivation for setting up such an experiment was two competing ideas in how to produce energy: the thermonuclear fusion reaction and the cold nuclear fusion reaction (CF).

To carry out thermonuclear fusion reactions in the planned experiment, an approach was proposed basing on the photodisintegration of deuterons in condensed deuterium under the action of gamma quanta with energies up to $10 \mathrm{MeV}$. In each deuteron photodecay event, a neutron and a proton are formed with energies determined by the reaction kinematics. The binding energy of the deuteron is $2.224 \mathrm{MeV}$. With the elastic interaction of photo-neutrons and photo-protons with gas deuterons, the latter acquire the energy $>40 \mathrm{keV}$, sufficient to launch thermonuclear reactions through the channels: $\mathrm{d}+\mathrm{d} \rightarrow{ }^{3} \mathrm{He}+\mathrm{n}+3.26 \mathrm{MeV}$ and $\mathrm{d}+\mathrm{d} \rightarrow$ $\mathrm{t}+\mathrm{p}+4.03 \mathrm{MeV}$. The resulting products of thermonuclear reactions, in their turn, give a part of their energy to the deuterons, and they again enter into thermonuclear fusion reaction. It was expected that under the action of gamma rays in deuterium, thermonuclear energy would be produced, sufficient to heat the reaction chamber to a high temperature.

The effect of heating the reaction chamber was also expected in the case of the implementation of cold fusion reactions [5]. Therefore, palladium was placed in the reaction chamber. It is known from literature [6] that the intensity of the reactions of $\mathrm{CF}$ enhances with the growing number of deuterium atoms per palladium atom. It was proposed to increase the concentration of deuterium in palladium with the help of the high gas pressure and its irradiation with braking gamma quanta. Moreover, the author of this article R.Wiśniewski registered an unexpected strong explosion of the high-pressure chamber while saturating the palladium powder with gaseous deuterium at a pressure of about $22 \mathrm{kbar}$ (private communication).

The use of intense gamma-ray fluxes turns out to be the most suitable method for photodecay and ionization of deuterium due to their high penetrating power through the thick walls of the high-pressure reaction chamber. Other radiation emissions do not possess such penetrating ability.

During the first and subsequent irradiations, there was no critical increase of the temperature or pressure in the reaction chamber. However, after irradiation unusual solid-state structures and "extraneous" chemical elements were found in the chamber, which were absent before the start of the experiment. The following elements were thus registered: $\mathrm{Na}, \mathrm{Mg}, \mathrm{Al}, \mathrm{Si}, \mathrm{P}, \mathrm{S}, \mathrm{Cl}, \mathrm{K}, \mathrm{Ca}$, Ti, V, Cr, $\mathrm{Fe}, \mathrm{Nb}, \mathrm{Ru}, \mathrm{Ag}, \mathrm{La}, \mathrm{W}, \mathrm{Pt}, \mathrm{Pb}$. Later, an experiment was carried out at a deuterium pressure of $1.2 \mathrm{kbar}$ [7-10].

Similar studies were performed with samples of other metals and alloys: $\mathrm{Al}, \mathrm{V}, \mathrm{Cu}, \mathrm{Sn}, \mathrm{Re}, \mathrm{YMn}_{2}$, in the form of cylinders and wires. The samples were in the atmosphere of gaseous deuterium at a pressure of hundreds, thousands of bars, and were irradiated with braking radiation with the $E_{\max }=10 \mathrm{MeV}$ and $E_{\max }=23 \mathrm{MeV}$ [11-15]. Positive results on the synthesis of new structures and "extraneous" elements in the deuterium atmosphere led to similar studies with palladium [16-18] and tin [19-21] cylinders in condensed hydrogen and with a palladium cylinder [22, 23] in condensed helium. The same studies were carried out in chambers with condensed pure gases: hydrogen [24-26], deuterium [27], helium [28-31] and xenon [32-36] when irradiated by $\gamma$-rays with energies up to the $E_{\max }=10 \mathrm{MeV}$. Experimental reviews in the $\mathrm{H}_{2}, \mathrm{D}_{2}, \mathrm{He}$ and $\mathrm{Xe}$ gases are presented in [37-39].

In this article, we present the processed and presented in an illustrative graphical form main results of the experiments on the synthesis of "extraneous" elements when irradiating palladium samples with the $E_{\max }=10 \mathrm{MeV}$ by braking gamma-rays in condensed deuterium with a pressure of 1.2 and $3 \mathrm{kbar}$, in hydrogen with a pressure of 0.5 and $2.5 \mathrm{kbar}$, and in helium with a pressure of $2.4 \mathrm{kbar}$. Here, for comparison, the results of experiments on the irradiation of pure gases without metal samples inside the reaction chambers are presented.

In this paper, the experiments were carried out and results discussed were obtained with the ideological organizational guidance and most active participation of A.Yu.Didyk to whom this article is dedicated. 


\section{RECEIVING BRAKING GAMMA RADIATION}

As a source of braking gamma radiation the electron accelerator microtron MT-25 of the Flerov Laboratory of Nuclear Reactions at JINR. The acceleration of electrons occurs in a pulsed mode with a pulse duration of $2.5 \mu$ s and a repetition frequency of $400 \mathrm{~Hz}$. The design of the microtron allows one to receive electron beams with energies from 5 to 24 $\mathrm{MeV}$. The maximum current of the electron beam at the target is $25 \mu \mathrm{A}\left(1.56 \cdot 10^{14} \mathrm{~s}^{-1}\right)$. After acceleration, an electron beam of $\varnothing 6-7 \mathrm{~mm}$ is released into the atmosphere through a $70 \mu \mathrm{m}$ titanium foil (1, Fig. 1), upon which irradiation takes place. In experiments, both the electron beam and radiations produced by convectors can be used: braking gamma radiation intensity of $10^{14} / \mathrm{s}$, fast neutrons with an intensity of $10^{12} / \mathrm{s}$, thermal neutrons with a flux density of $10^{9} /$ $\mathrm{s} \cdot \mathrm{cm}^{2}$, resonant neutrons with a flux density of $8 \cdot 10^{7}$ $/ \mathrm{s} \cdot \mathrm{cm}^{2}$.

To obtain the braking gamma-rays, electrons bombard a tungsten converter - a disk with a thickness of 1 to $3.8 \mathrm{~mm}$ and $\varnothing 40 \mathrm{~mm}$ (3, Fig. 1). The electron beam enters the converter, passing through the diaphragm with a hole of $\varnothing 12 \mathrm{~mm}(2$, Fig. 1) and a thickness of $18 \mathrm{~mm}$. The converter is fixed in a holder with the help of an aluminum cylinder with a thickness of $8-25 \mathrm{~mm}$, which also serves to absorb low-energy electrons (4, Fig. 1). The diaphragm and the holder of the converter with an aluminum absorber are cooled with running distilled water. In the process of irradiation, the electron current on the Al-absorber and on the diaphragm is controlled. In all experiments, a tungsten converter with a thickness of $2.8 \mathrm{~mm}$ and an electron absorber $-25 \mathrm{~mm}$ were used.

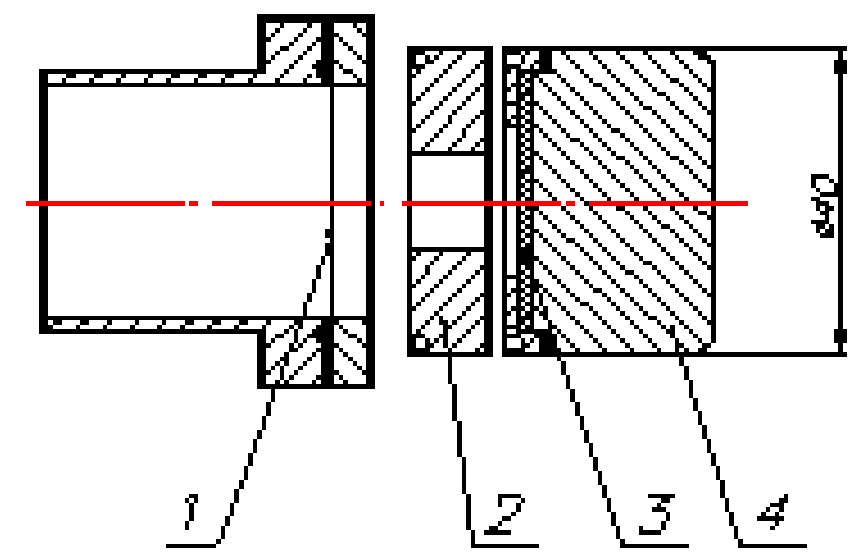

Fig. 1. Extraction of the electron beam from the electron guide and its convertion into a beam of gamma quanta.

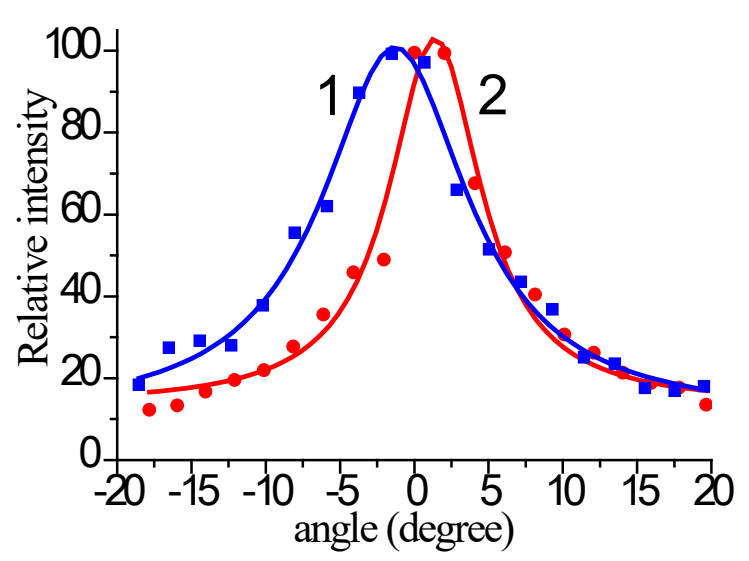

Fig. 2. The gamma-quanta beam divergence.

The gamma quanta beam divergence at halfheight of intensity is horizontally $10^{\circ} \pm 1^{\circ}$ (Fig. 2, curve 1 ) and $8^{\circ} \pm 1^{\circ}$ along the vertical (Fig. 2, curve 2). The difference in half widths in the horizontal and vertical planes is explained by the different angular divergence of the electron beam in these planes. Experimentally, the divergence was determined by the method of activating targets: uranium with a threshold of $6 \mathrm{MeV}$ and nickel with a threshold of $12.2 \mathrm{MeV}$, completely covering the braking radiation beam. In both cases, the angular distribution is approximated with good accuracy by the Lorentz distribution. The values obtained in the experiment are in good agreement with the calculation of the angular distribution of braking using the Giant package, which predicts an angular divergence of the beam of 9.9 degrees, and the authors of [40].

Fig. 3 shows the calculated energy spectrum of braking radiation emitted in a $10^{\circ}$ cone for electrons with energies of $10,14,18$, and $22 \mathrm{MeV}$ on a $3 \mathrm{~mm}$ thick tungsten convector [41]. The intensities of gamma quanta from $1 \mathrm{MeV}$ to the $E_{\max }$ for these

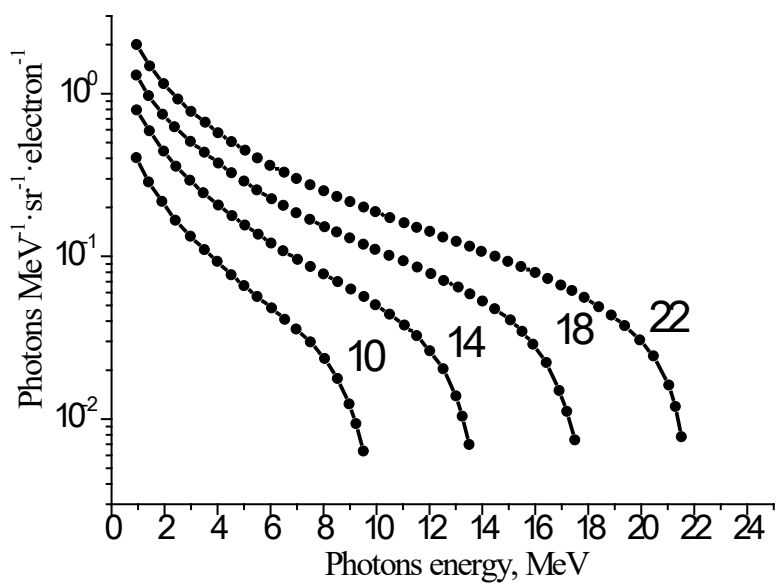

Fig. 3. A gamma-quanta spectrum for electron energies of 10, 14, 18 and $22 \mathrm{MeV}$. 
electron energies, normalized to the intensity at $\mathrm{E}=10 \mathrm{MeV}$, correspond 1: 4.52: 13.24: 32.13. For the range of gamma quanta from 1 to $10 \mathrm{MeV}$, the intensities correspond to 1: 4.50: 13.04: 31.03.

\section{THE METHODS OF THE EXPERIMENTS}

The irradiation of palladium samples in a medium of condensed gases was carried out using a braking gamma-quantum with the $E_{\max }=10 \mathrm{MeV}$. The energy range of gamma quanta $(<10 \mathrm{MeV})$ lies below the characteristic excitation energies in the atomic nuclei of a giant dipole resonance. This avoids the activation of the structural materials of the reaction chambers. The decay of a giant dipole resonance occurs mainly with the emission of a proton or a neutron, often followed by the formation of radioactive isotopes. In the experiments, the chamber shown in Fig. 4 was used. Each experiment used its own chamber. The inner diameter of the chambers was $4 \mathrm{~mm}$, the length was $21 \mathrm{~mm}$, the volume was $0.264 \mathrm{~cm}^{3}$. The palladium samples (9, Fig. 4) with a diameter of $3.8-3.9 \mathrm{~mm}$ and a length of 4-5.5 mm (of volume 0.045-0.065 $\mathrm{cm}^{3}$ ) had a purity of $\sim 99.995 \%$. The atomic mass of $\mathrm{Pd}$ is 106.42; the density of palladium is 12.02 $\mathrm{g} / \mathrm{cm}^{3}$. The maximum concentrations of impurities $\left(10^{-6}\right.$ mass in $\left.\mathrm{ppm}\right)$ in palladium are as follows: $\mathrm{Ca}$, $\mathrm{Zn}, \mathrm{Ag}<3$; Mg, Mn, Ni, Pb, Bi < 5; Si, As, Sn, Sb, $\mathrm{Ru}, \mathrm{Rh}, \mathrm{Ir}, \mathrm{Pt}<10 ; \mathrm{Cu}(12), \mathrm{Al}(15), \mathrm{Fe}(19), \mathrm{Au}(48)$. In the experiments, brass $(\mathrm{Zn}+\mathrm{Cu})$ or copper $(\mathrm{Cu})$ with a purity of $99.99 \%$ was used as sleeves (8, Fig. 4) and collectors (12, Fig. 4). The composition of the brass sleeves and the collectors measured by x-ray micro-probe analysis included: $\mathrm{Cu}-59.61$ and $\mathrm{Zn}$ - 40.39 (at.\%). The pressure in the chambers varied from 0.5 to $3 \mathrm{kbar}$. Table 1 presents the parameters of exposure.

After irradiation, the gas was released into the atmosphere and the chamber was opened. In all experiments, after the end of irradiation new objects

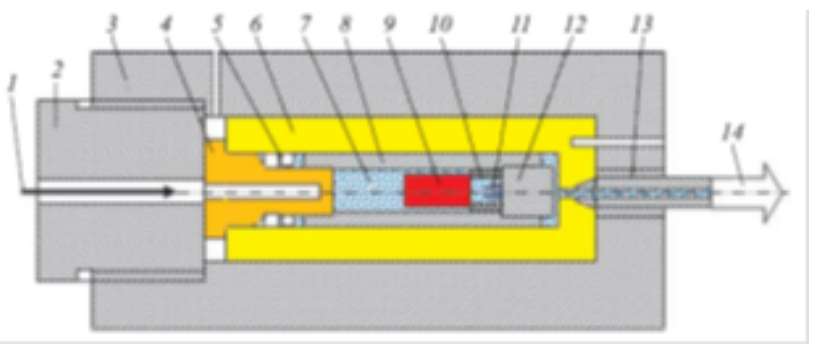

Fig. 4. The high pressure gas chamber with a palladium sample.
Table 1

Parameters of the experiments.

\begin{tabular}{|l|c|c|c|c|c|}
\hline Chamber & $\mathrm{D} 1$ & $\mathrm{D} 2$ & $\mathrm{H} 1$ & $\mathrm{H} 2$ & $\mathrm{He}$ \\
\hline Electron energy, MeV & 9.3 & 10 & 10.3 & 9.7 & 10 \\
\hline Exposure time, hours & 6 & 18 & 7 & 14 & 96 \\
\hline Average current, $\mathrm{mA}$ & 7 & 12 & 2.5 & 20.5 & 20.5 \\
Electron flux, $10^{13} \mathrm{c}^{-1}$ & 4.4 & 7.5 & 1.6 & 12.8 & 12.8 \\
\hline Integral charge, $\mathrm{C}$ & 0.15 & 0.78 & 0.14 & 1.03 & 7.1 \\
\hline Pressure, kbar & 3 & 1.2 & 2.5 & 0.5 & 2.4 \\
\hline Atomic density, 1022at/cm ${ }^{3}$ & 5.2 & 2.95 & 9.12 & 1.82 & 2.23 \\
\hline Weight density, g/cm ${ }^{3}$ & 0.155 & 0.088 & 0.154 & 0.0307 & 0.15 \\
\hline$\varnothing$ Pd-cylinder, $\mathrm{mm}$ & $3.8 \times 5$ & $3.8 \times 5.5$ & $3.8 \times 5$ & $3.8 \times 5$ & $3.9 \times 5$ \\
\hline Material of sleeve and collector & $\mathrm{Zn}+\mathrm{Cu}$ & $\mathrm{Zn}+\mathrm{Cu}$ & $\mathrm{Zn}+\mathrm{Cu}$ & $\mathrm{Zn}+\mathrm{Cu}$ & $\mathrm{Cu}$ \\
\hline References & $1-3$ & $7-10$ & 16 & $17-18$ & $22-23$ \\
\hline
\end{tabular}

were found in the reaction chambers: microparticles with the size from $0.5 \mu \mathrm{m}$ to $1 \mathrm{~mm}$, and anomalous solid-state structures were observed on the walls of the reaction chambers and on the surface of the palladium cylinder. Solid-state structures were: crystalline, amorphous and spherical structures; ring-shaped, filamentery and tubular formations; loose and hard inclusions and influx on the surfaces of the reaction chamber parts. Using the methods of scanning electron microscopy (SEM) and x-ray micro-probe analysis (XRMPA), the elemental compositions of the chamber parts were investigated: on the inner surfaces of the entrance window made of beryllium bronze $\left(\mathrm{Cu}_{0.92} \mathrm{Be}_{0.08}\right)$ (4, Fig. 4), at the sleeves and collectors, at the $\mathrm{Cu}_{84} \mathrm{Mn}_{14} \mathrm{Ni}_{2}$ manganine foils (10, Fig. 4), as well as at the anomalous structures and microparticles formed as a result of irradiation of the palladium cylinder surface and the chamber inner surfaces.

In most of the objects, when they were studied using the SEM and XRMPA methods, "extraneous" chemical elements, which were absent in the reaction chambers before the onset of irradiation, were detected. For each object selected for the study: microparticles or a solid-state structure, several measurements of XRMPA were carried out in different regions of their surface. Each such measurement corresponded to its own set of chemical elements with its own concentration. The total number of XRMPA measurements for a particular experiment was several dozens. When processing the data, we first obtained averaged concentrations of chemical elements separately for each part of the reaction chamber in contact with the condensed gas. Taking into account the entire set of data obtained by the XRMPA method, it 
can be argued that there is no significant difference in the distribution of chemical elements for the input window, sleeve, collector, manganin foil, and the particles. In this article, we also present in the form of histograms the concentrations of chemical elements averaged over all measurements performed for this experiment.

SEM and XRMPA studies were conducted at three independent certified laboratories: at the analytical center of the D.V. Skobeltsyn INP, Lomonosov MSU; at the Research Institute of Advanced Materials and Technologies, and at the Fiber Optics Research Center of the Russian Academy of Sciences. The energy of the electron beam exciting the x-rays ranged from 10 to $20 \mathrm{keV}$. The penetration depth of the electron beam was 1-2 $\mu \mathrm{m}$. The measurements were carried out using two modes: "at a point" and "over the area". For the mode "at the point", the measurement area was $\sim 1-4 \mu \mathrm{m} 2$. For the "area" mode, the measurement area was more than $20 \times 20 \mu \mathrm{m}^{2}$.

We note several important points in our SEM and XRMPA studies:

- the program for proccessing spectra obtained using XRMPA selects the lines only of those elements which exceed no less than thrice the measurement error;

- the program calculates the estimated element concentrations in weight and atomic percent if the spectrum contains the main characteristic $\mathrm{x}$-ray lines of this element;

- the concentrations of "extraneous" elements in the objects given in the article are not quantitative but qualitative. The choice of objects for measurement was purely subjective. As a rule, the most appealing, bright and light objects with the presence of elements of large atomic numbers were measured;

- microparticles and structures located on the surfaces of collectors, inserts and sleeves were selected as objects for measurements. Analysis of the element compositions at the surfaces of the palladium cylinder was made as well;

- for reliable spectra proccessing, a set of considerable amount of statistical data are required, which was not always done in our measurements;

the dimensions of the studied structures were far greater than the regions of excitation and emission of characteristic x-radiation. Therefore the measurements done cannot correspond to the

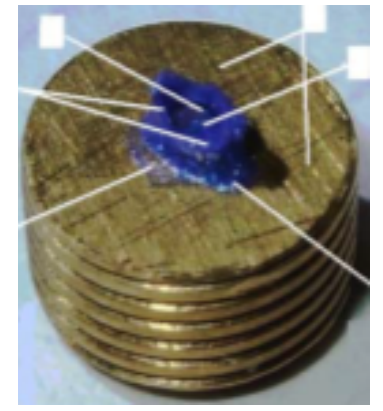

$a$

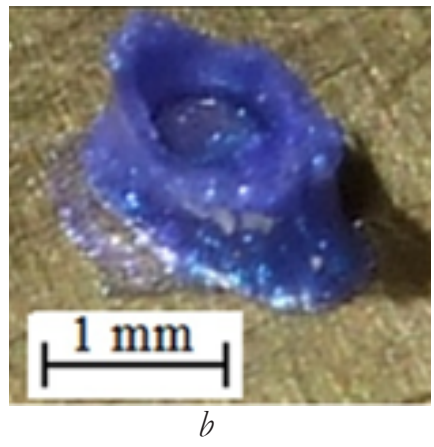

Fig. 5. Photos of the synthesized sample: a) at the brass collector; b) enlarged image.

element concentration in the entire volume of the measured objects;

- during the measurements of the objects at the points with local concentrations of "extraneous" chemical elements could amount to several tens percent. Besides, such measurements have certain restrictions relating to spatial resolutions of the equipment used.

\section{THE EXPERIMENTS WITH PALLADIUM IN DEUTERIUM}

In the very first experiment, after irradiating a sample of palladium at a deuterium pressure of 3 kbar, when the chamber D1 was opened (Table 1), a synthesized blue object was detected on the brass collector $5 \mathrm{~mm}$ in diameter, (Fig. 5a) and (Fig. 5b). The object was shaped like a "volcano with a crater" with smooth walls. At the top of the "crater", frozen drops were observed, and at its bottom, various structures in the form of plates (Fig. 6a) and crystalline formations (Fig. 6b). Here and hereinafter, the widths of photographs are given in brackets. The synthesized object had dielectric properties. For SEM and XRMPA, this required deposition of a gold layer of $\mathrm{Au} \sim 0.1 \mu \mathrm{m}$. The x-ray micro-probe analysis revealed "extraneous" chemical elements in the object which had been absent in the reaction

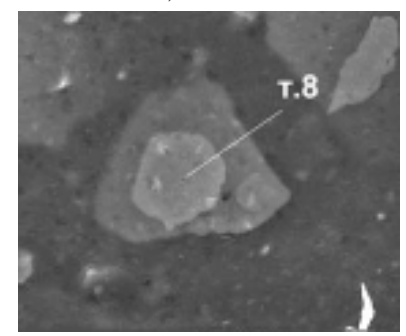

$a$

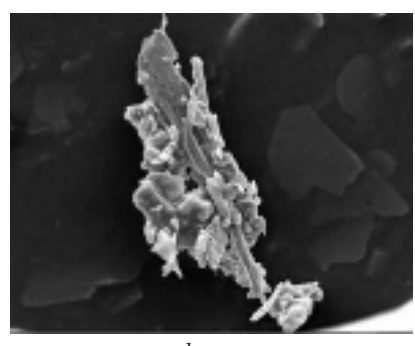

$b$
Fig. 6. The SEM images of the structures found at the bottom of the "crater": a) in the form of plates a (the photo width is $60 \mu \mathrm{m}$ ) and b) the crystalline formations (the photo width is $150 \mu \mathrm{m}$ ). 


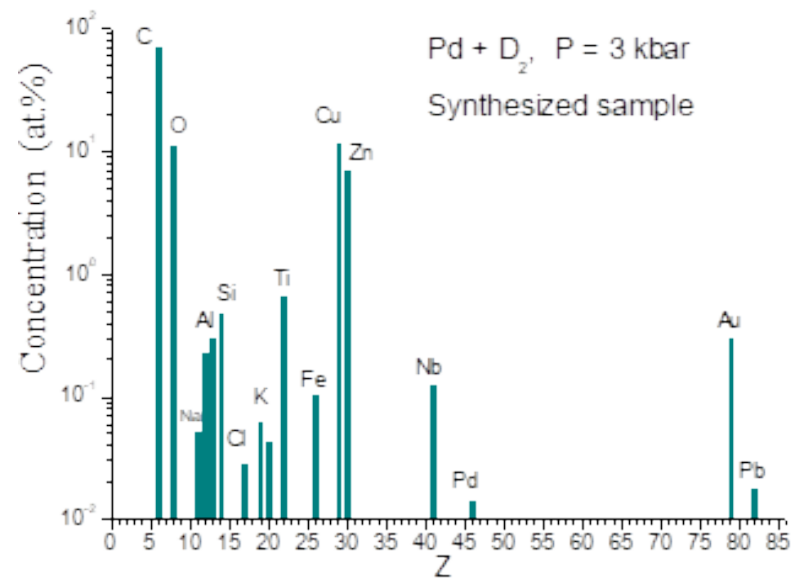

Fig. 7. The concentrations of chemical elements in the synthesized sample (12 measurements).

chamber before the start of the experiment. Fig. 7 shows the concentrations of chemical elements in the synthesized sample, averaged over 12 measurements, which were carried out both on its surface and in the various structures found inside the crater. It is noteworthy that the synthesized object mainly consists of carbon, oxygen and titanium. Subsequent $\mathrm{x}$-ray diffraction analysis showed that titanium is present in the synthesized object in the form of dioxide $\left(\mathrm{TiO}_{2}\right)$.

The irradiated Pd-cylinder has undergone significant changes. The SEM images of the original and irradiated surfaces of the Pd-cylinder are shown in Fig. 8a,b. The surface of the Pd-cylinder, especially close to the synthesized object, turned from smooth into non-uniform, consisting of individual clusters, with a lot of cracks in the surface and, moreover, with a modified composition of the chemical elements. Fig. 9 presents atomic percent concentrations of chemical elements averaged over 12 XRMPA measurements of the palladium cylinder surface.

The changes affected the surface structure and the content of chemical elements, both at the entrance window (4, Fig. 4), made of beryllium bronze, and

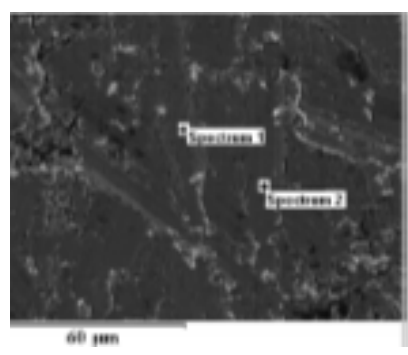

$a$

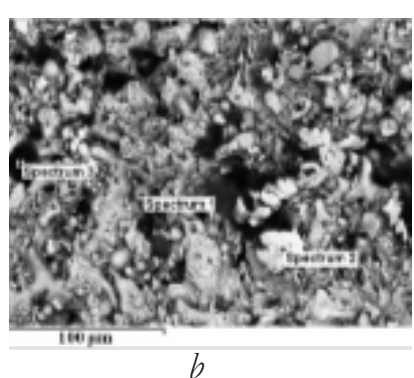

b
Fig. 8. SEM images of the Pd-cylinder surfaces: a) before the irradiation and b) after the irradiation.

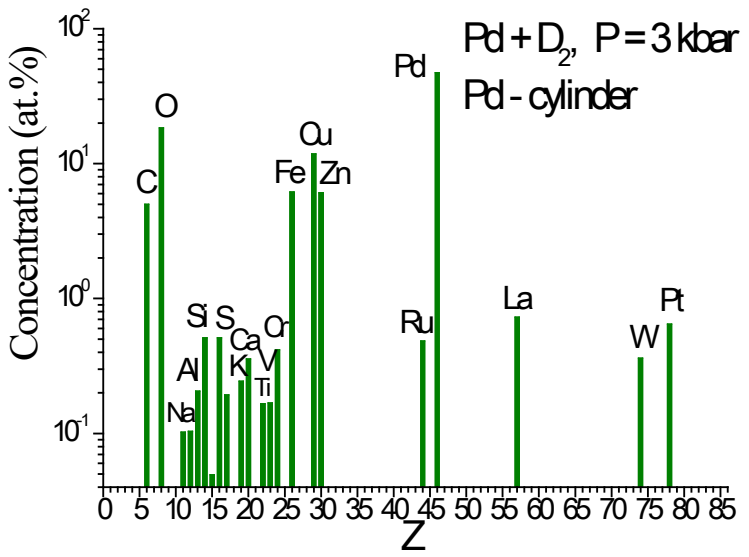

Fig. 9. The concentrations of chemical elements at the $P d$ cylinder (12 measurements).

at the brass sleeve (8, Fig. 4). Fig. 10 shows the concentrations of chemical elements at the entrance window, averaged over 5 measurements, and for the brass sleeve, averaged over 10 measurements.

Fig. 11 gives the concentrations of chemical elements averaged over all 39 measurements. Thus, the following chemical elements were registered in the reaction chamber: $\mathrm{C}, \mathrm{O}, \mathrm{Na}, \mathrm{Mg}, \mathrm{Al}, \mathrm{Si}, \mathrm{P}, \mathrm{S}, \mathrm{Cl}$, $\mathrm{K}, \mathrm{Ca}, \mathrm{Ti}, \mathrm{V}, \mathrm{Cr}, \mathrm{Fe}, \mathrm{Nb}, \mathrm{Ru}, \mathrm{Ag}, \mathrm{La}, \mathrm{W}, \mathrm{Pt}, \mathrm{Pb}$.

For comparison, Fig. 12 shows the averaged concentrations of chemical elements obtained in an experiment on irradiating a chamber with deuterium at a pressure of $2.2 \mathrm{kbar}$ without a Pd-cylinder inside it [27]. Averaging was carried out over 42 measurements performed for the structures of the entrance window, the sleeve, the collector, and the synthesized microparticles. The internal dimensions of the chamber filled with deuterium were: length - $15 \mathrm{~mm}$, diameter $-8 \mathrm{~mm}$, volume $-0.75 \mathrm{~cm}^{3}$. The sleeve and the collector were made of pure copper, $99.99 \%$. The irradiation was carried out during 49

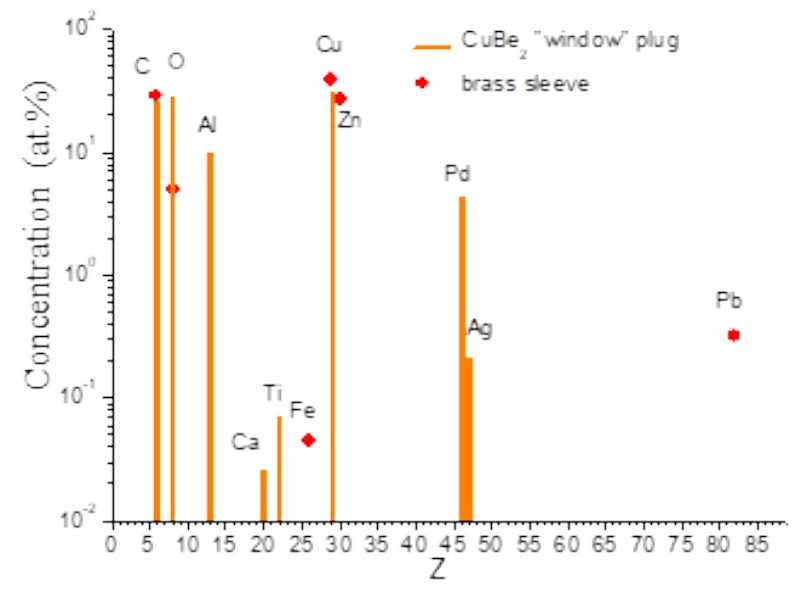

Fig. 10. The concentrations of chemical elements at the surface of the "entrance window" and the sleeve. 


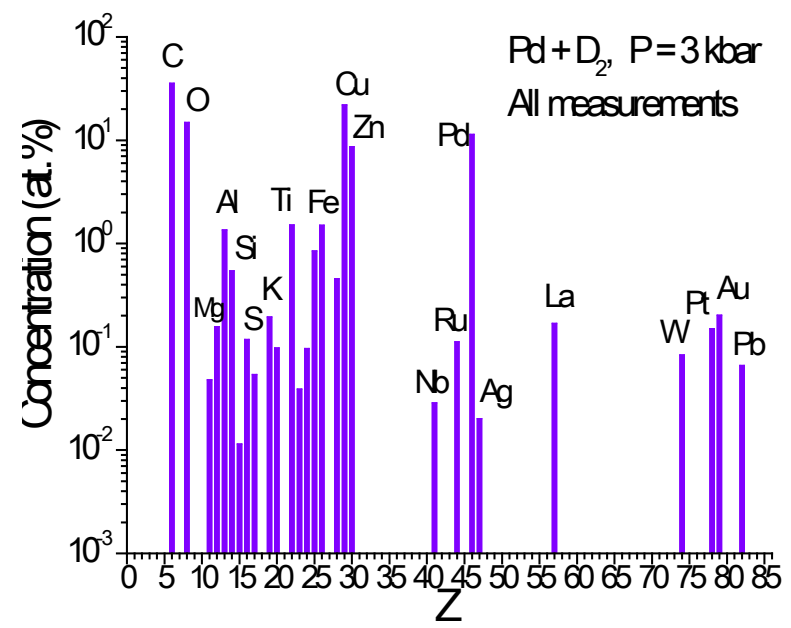

Fig. 11. The concentrations of chemical elements (39 measurements).

hours. The electron beam energy was $10 \mathrm{MeV}$. The current of the electrons was $(1.2-1.3) \cdot 10^{14} \mathrm{~s}^{-1}$.

The experiment described above was repeated (D2, Tab. 1), but with a deuterium pressure of 1.2 kbar and an irradiation duration of 18 hours. The most impressive result of this experiment was the detection of $\mathrm{a}_{82} \mathrm{~Pb}$ layer covering all the inner surfaces of the reaction chamber and microparticles up to 50 microns in size, consisting mainly of lead. Fig. 13 presents averaged concentrations of chemical elements in atomic percentage from the 44th XRMPA measurements of the palladium cylinder surface. Without palladium, the weight concentration of lead is $\sim 36 \%$, oxygen $\sim 29 \%$.

Fig. 14 shows SEM images of one of the characteristic elliptically-shaped formations with a size of $17 \times 22 \mu \mathrm{m}$ (Fig. 14a) and individual lead microparticles (Fig. 14b) found on the surface of the brass collector. The lead concentration over the area of $5.3 \times 6.3 \mu \mathrm{m}$, noted as "spectrum 1" (Fig. 14a),

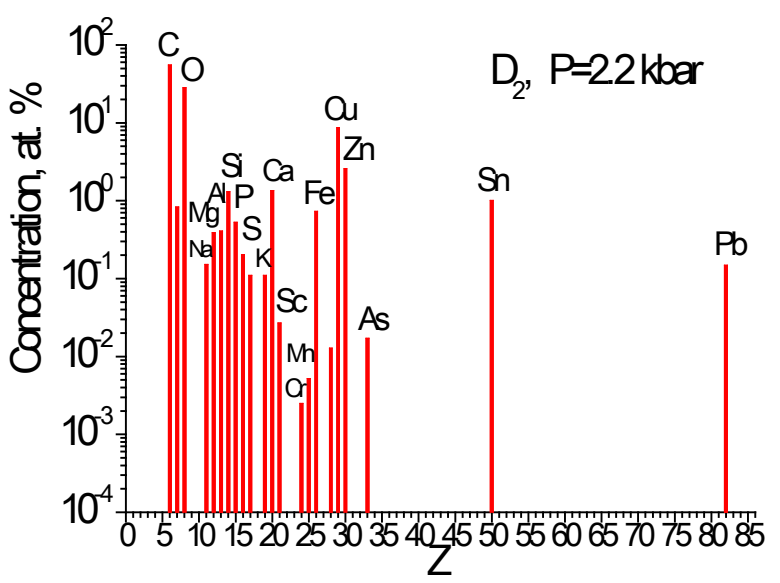

Fig. 12. The average concentrations of chemical elements over 42 measurements.

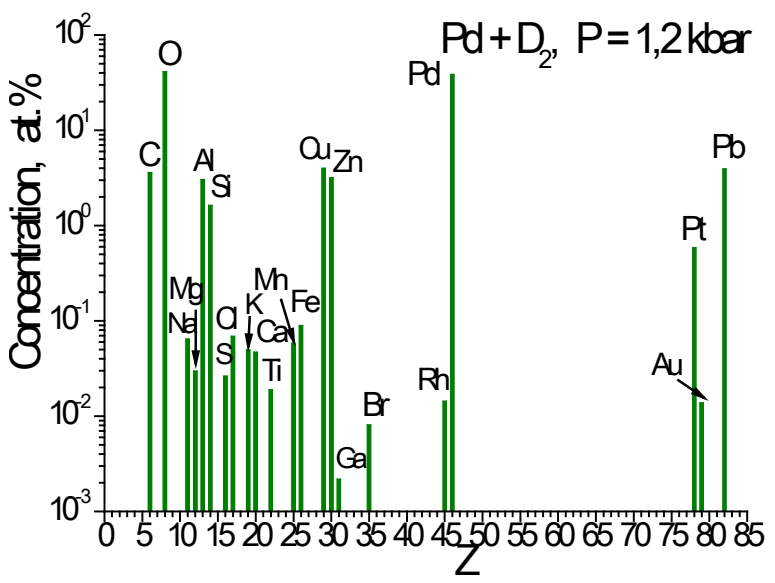

Fig. 13. The concentrations of chemical elements at the Pdcylinder (44 measurements).

is 21.3 wt. $\%$. Lead concentrations, measured at points 1 and 2 (Fig. 14b), are 65.1 and 10.9 wt.\%, respectively. Lead was not detected at point 3. It contains: copper-62.9 and zinc-37.1 wt.\%. Table 2 shows the concentrations of chemical elements averaged over 15 measurements made for different microparticles, and 8 measurements made at points or from the area next to the microparticles. The lead concentration in the microparticles varied from 31.5 to $71.9 \mathrm{wt} . \%$, and in the areas near the microparticles, from 0 to 10.9 wt. \%. In five measurements out of 23 $(15+8),{ }_{14} \mathrm{Si},{ }_{20} \mathrm{Ca},{ }_{26} \mathrm{Fe}$ were registered. Subsequent studies carried out by the method of secondary mass-ion spectroscopy showed that the isotopic composition of the synthesized lead does not differ from the natural composition within the limits of measurement errors [40]. In the same studies, lines corresponding to the masses of protactinium $\left({ }^{231} \mathrm{~Pa}\right)$ and curium $\left({ }^{246} \mathrm{Cm}\right)$ were recorded in the mass spectrum.

The initial weight of the Pd-cylinder was 0.7509 g. After irradiation, its weight decreased by $0.03245 \mathrm{~g}$, which is $4.3 \%$. The authors of [9] believe that the decrease in the weight of the Pd sample is mainly due to the formation of lead: $32450 \mu \mathrm{g} \mathrm{36 \%}$ $=11682 \mu \mathrm{g}$ or $3.4 \cdot 10^{19} \mathrm{~Pb}$ atoms. The impurity of

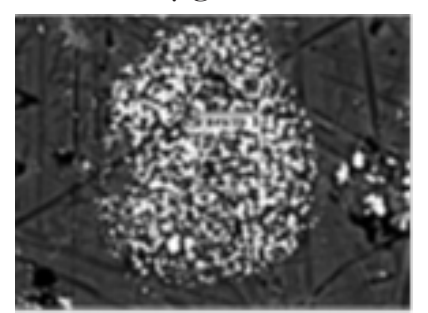

$a$

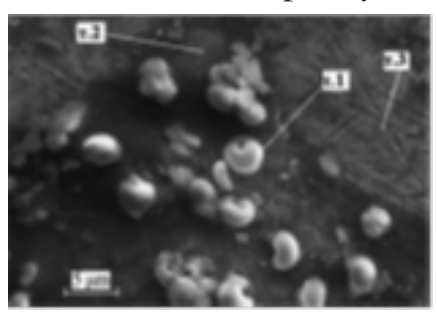

b
Fig. 14. SEM images: a) an elliptical formation consisting of lead microparticles; b) lead microparticles. 
Table 2 Averaged concentrations of chemical elements for the microparticles and at the surface of the brass collector.

\begin{tabular}{|l|l|c|c|c|c|l|}
\hline \multicolumn{1}{|c|}{ Element } & $\mathrm{C}$ & $\mathrm{O}$ & $\mathrm{Cu}$ & $\mathrm{Zn}$ & $\mathrm{Pb}$ & \multicolumn{1}{c|}{$\%$} \\
\hline $\begin{array}{l}\text { Microparticles, } \\
15 \text { meas. }\end{array}$ & 9.88 & 15.78 & 9.91 & 7.88 & 56.27 & weight. \\
\cline { 2 - 7 } & 34.92 & 41.81 & 6.63 & 5.12 & 11.52 & atom \\
\hline $\begin{array}{l}\text { Brass surface, } \\
8 \text { meas. }\end{array}$ & 14.6 & 6.76 & 43.12 & 27.0 & 8.53 & weight. \\
\cline { 2 - 7 } & 43.92 & 15.24 & 24.48 & 14.9 & 1.47 & atom \\
\hline
\end{tabular}

$\mathrm{Pb}$ in the palladium sample before irradiation was $<5 \mathrm{ppm}$ or $<3.7 \mu \mathrm{g}$. The number of $\gamma$-quanta with energy from 1 to $10 \mathrm{MeV}$ at the entrance to the internal volume of the reaction chamber during the entire irradiation period is estimated as $\sim 1.2 \cdot 10^{17}$, which $<<3.4 \cdot 10^{19} \mathrm{~Pb}$ atoms. From this we can conclude that gamma quanta stimulate the launch of other energy processes leading to the synthesis of "extraneous" chemical elements.

Studies of the chemical composition of the synthesized structures on the surfaces of the brass collector (25 measurements), the entrance window (6 measurements), sleeve (17 measurements) and manganin foil (10 measurements) showed the presence of "extraneous" chemical elements in them. A feature of these measurements was the detection of a large amount of silver $(\mathrm{Ag})$ in the structures and microparticles, up to $98.4 \%$ of their weight. Fig. 15 shows the concentrations of chemical elements averaged over these 58 measurements.

Fig. 16 shows the concentrations of chemical elements averaged over all 102 measurements. The following elements which were previously absent in the reaction chamber were recorded at the surfaces of the chamber, Pd cylinder, and microparticles: ${ }_{6} \mathrm{C}$,

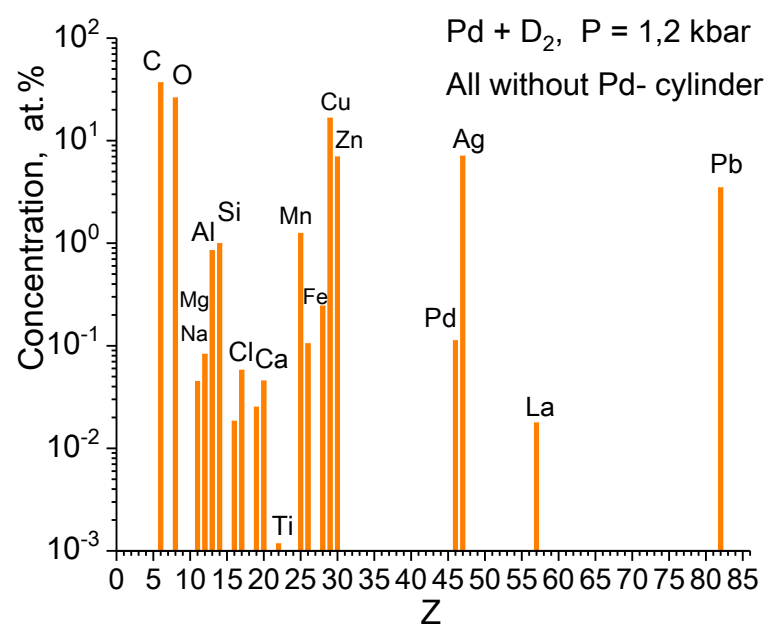

Fig. 15. The concentrations of chemical elements (58 measurements).

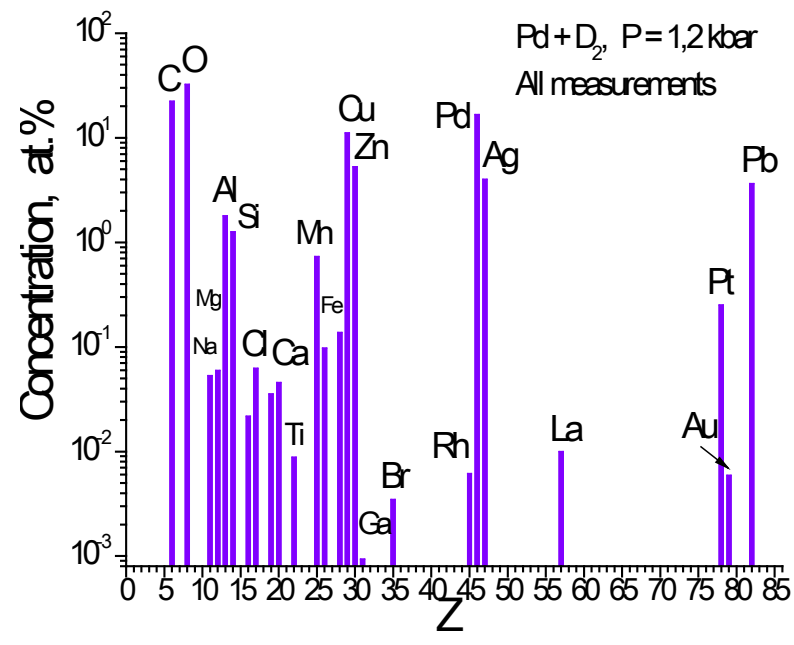

Fig. 16. The concentrations of chemical elements (102 measurements).

${ }_{8} \mathrm{O},{ }_{11} \mathrm{Na},{ }_{12} \mathrm{Mg},{ }_{13} \mathrm{Al},{ }_{14} \mathrm{Si},{ }_{16} \mathrm{~S},{ }_{17} \mathrm{Cl},{ }_{19} \mathrm{~K},{ }_{20} \mathrm{Ca},{ }_{22} \mathrm{Ti},{ }_{24} \mathrm{Cr}$, ${ }_{26} \mathrm{Fe},{ }_{27} \mathrm{Co},{ }_{31} \mathrm{Ga},{ }_{35} \mathrm{Br},{ }_{45} \mathrm{Rh},{ }_{47} \mathrm{Ag},{ }_{78} \mathrm{Pt},{ }_{79} \mathrm{Au}$, and ${ }_{82} \mathrm{~Pb}$.

\section{THE EXPERIMENTS WITH}

\section{PALLADIUM AND TIN IN HYDROGEN}

In the experiment with a pressure of $2.5 \mathrm{kbar}(\mathrm{H} 1$, Tab. 1), chamber $\mathrm{H} 1$ was located at a distance of $5 \mathrm{~mm}$ from the electron absorber $-25 \mathrm{~mm}$. After irradiation with gamma quanta, the chamber was irradiated for 12 minutes with electrons at a current of $(1.55-2.1) \cdot 10^{13} \mathrm{~s}^{-1}$. After that, the pressure in the chamber decreased by 80 bar.

In both experiments with a hydrogen pressure of $0.5 \mathrm{kbar}$ (H2, Tab. 1) and $2.5 \mathrm{kbar}$ after the end of the irradiation, newly formed structures were found in the reaction chambers. The side and end surfaces of the Pd-cylinders had significantly changed: they had cracks, craters and microparticles. Fig. 17 shows SEM images of the two cracks. Inside and along the edges of these formations and also, on the surfaces of the Pd-cylinders, "extraneous" chemical elements were discovered which were formed as a result of irradiation. Fig. 18 presents the averaged over 15 measurements concentrations of the synthesized chemical elements found on the Pd cylinder at
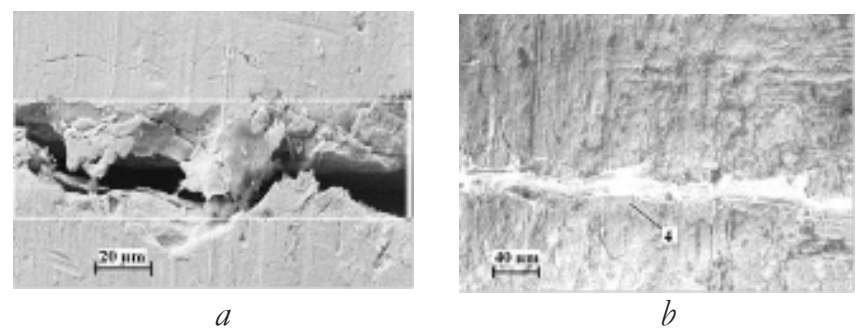

Fig. 17. a) a crack on the side surface of the Pd-rod; b) a narrow crack filled with synthesized elements. 


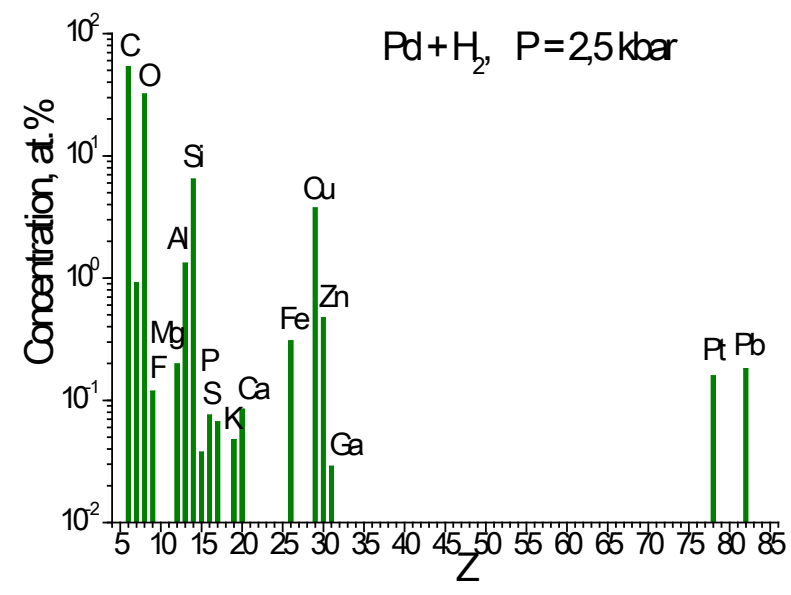

Fig. 18. The concentrations of chemical elements at the Pdcylinder (15 measurements).

the pressure $\mathrm{P}=2.5 \mathrm{kbar}$, excluding palladium. Measurements are made on the areas from 16 to $5600 \mu \mathrm{m}^{2}$. Fig. 19 shows a comparison of the average element concentrations for the Pd-cylinders measured in the experiments with the hydrogen pressure 0.5 and $2.5 \mathrm{kbar}$. For the experiment performed at the pressure $\mathrm{P}=0.5 \mathrm{kbar}$, the element concentrations averaged over 6 measurements of different objects made "at points" are given [17].

Fig. 20 shows a comparison of the average element concentrations measured in the microstructures found at the entrance windows, brass collectors and microparticles in the experiments with the hydrogen pressure 0.5 and $2.5 \mathrm{kbar}$. For the experiment at the pressure $\mathrm{P}=2.5 \mathrm{kbar}$, the averaging was performed over 4 measurements. For the experiment performed at the pressure $\mathrm{P}=0.5$ kbar, the element concentrations are averaged over 15 measurements of different objects. Along with light chemical elements from carbon ${ }_{6} \mathrm{C}$ to zinc ${ }_{30} \mathrm{Zn}$,

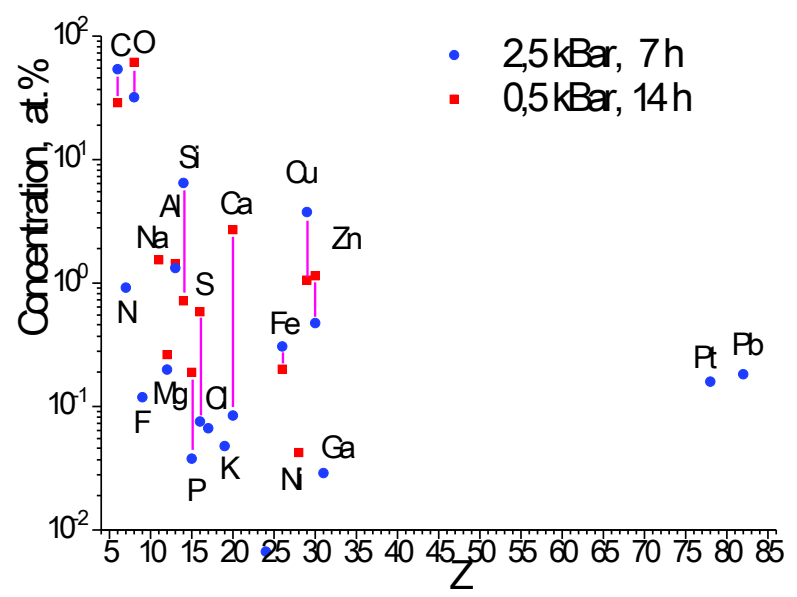

Fig. 19. A comparison of the concentrations of chemical elements at the Pd-cylinder.

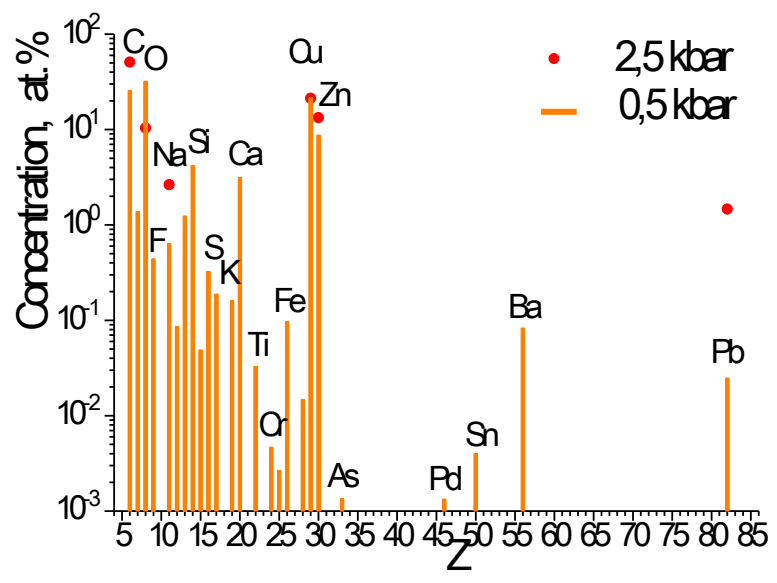

Fig. 20. A comparison of concentrations of chemical elements for microscopy.

in the experiment with $\mathrm{P}=0.5 \mathrm{kbar}$, arsenic $\left({ }_{33} \mathrm{As}\right)$, tin $\left({ }_{50} \mathrm{Sn}\right)$, barium $\left({ }_{56} \mathrm{Ba}\right)$, and lead $\left({ }_{82} \mathrm{~Pb}\right)$, were found.

Measurement of one of the synthesized structures over the area $35 \times 28 \mu \mathrm{m}^{2}$ was done by an electron beam along an $\sim 2 \mu \mathrm{m}$ strip through its center from one edge to another. Based on the many $\mathrm{x}$-ray spectra obtained, the concentration distribution of chemical elements along the strip was determined in [18]. In this study, along with such elements as barium and lead, the x-ray spectra processing program found lines corresponding to protactinium $\left({ }_{91} \mathrm{~Pa}\right)$. The two Pa peaks are clearly visible in Fig. 21 on the right. Protactinium $\left({ }^{231} \mathrm{~Pa}\right)$ is a radioactive element, usually resulting from the alpha decay of the $\left({ }^{235} \mathrm{U}\right)$ uranium isotope. ${ }^{235} \mathrm{U}$ has a half-life of $7 \cdot 10^{8}$ years and an isotopic content of $0.72 \%$. If protactinium were a daughter product of alpha decay of ${ }^{235} \mathrm{U}$, then we would have to observe in the set of x-ray spectra of the uranium line and, most likely, thorium $\left({ }^{230} \mathrm{Th}\right)$, as a result of alpha decay of ${ }^{234} \mathrm{U}$. Since such lines were not recorded in the spectra, it is very likely that protactinium was synthesized independently.

Fig. 22 shows the total averaged over 40 measurements element concentrations found at the palladium cylinder (19 measurements) and at the microstructures (21 measurements).

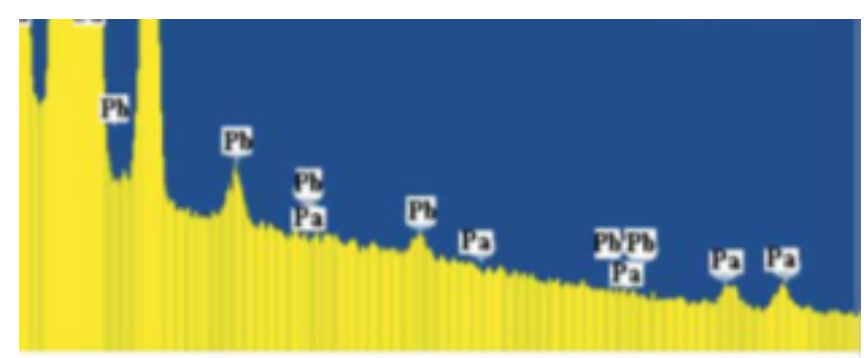

Fig. 21. The total $x$-ray spectrum after scanning. 


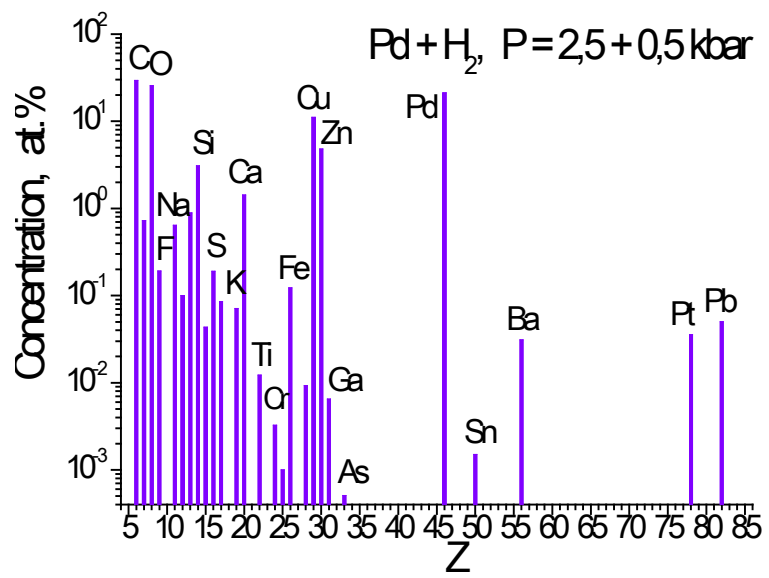

Fig. 22. The concentrations of chemical elements $(40$ measurements).

For comparison, Fig. 23 presents concentrations of chemical elements averaged over 35 measurements and obtained in two experiments with pure hydrogen $\left(\mathrm{H}_{2}\right)$ at the pressure 1 and $3.4 \mathrm{kbar}$ [39]. Irradiation was carried out for 14 and 62 hours, respectively, at the electron current $(1.2-1.5) \cdot 10^{14} \mathrm{~s}^{-1}$. The electron beam energy was $10 \mathrm{MeV}$.

For completeness, we present here the results of an experiment on the irradiation of tin $\left({ }_{50} \mathrm{Sn}\right)$ with gamma quanta in condensed hydrogen [19-21]. A sample of natural $\mathrm{Sn}$ with a purity of $99.9 \%$ was a cylinder with a diameter of $9.5 \mathrm{~mm}$, a length of $17 \mathrm{~mm}$, and a weight of $8.5731 \mathrm{~g}$. On both sides, the cylinder was fixed with two collectors made of beryllium bronze. The inner chamber, the sleeve for the reaction products and the entrance window were also made of beryllium bronze. The initial hydrogen pressure inside the reaction chamber was $3.5 \mathrm{kbar}$. At this pressure, the mass density of hydrogen was $0.0868 \mathrm{~g}^{\cdot} \mathrm{cm}^{-3}$, and the atomic density of hydrogen was $5.186 \cdot 10^{22}$ at. $\mathrm{H} \cdot \mathrm{cm}^{-3}$. The irradiation energy of

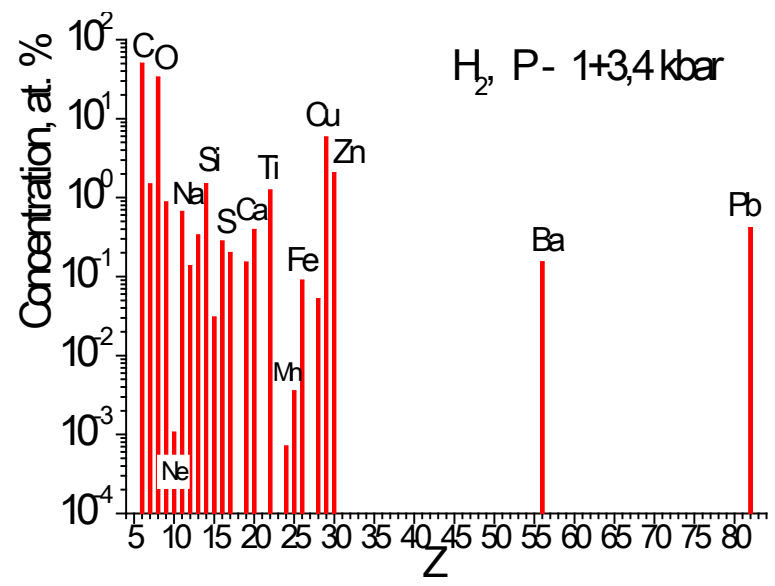

Fig. 23. The element concentrations for two experiments with $\mathrm{H}_{2}$ (35 measurements).

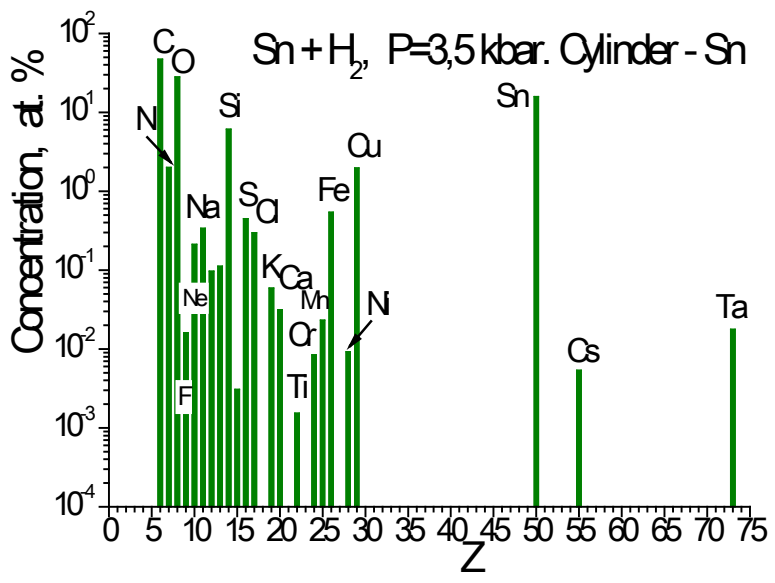

Fig. 24. The concentrations of chemical elements at the $S n$ cylinder (13 measurements).

electrons was $\mathrm{E}=10 \mathrm{MeV}$, and the current was varied within (1.3-1.5) $10^{14} \mathrm{~s}^{-1}$. Irradiation was carried out for $2.51 \cdot 10^{5} \mathrm{~s}(\sim 70 \mathrm{~h})$. The hydrogen pressure in the chamber after irradiation was 3.0 kbar. After opening the chamber, 30 black particles fell out of it. All surfaces of the parts of the reaction chamber, which had contact with hydrogen, and a significant part of the synthesized particles were investigated by SEM and XRMPA.

Fig. 24 shows the element concentrations averaged over 13 measurements of the synthesized structures found at the surface of the tin cylinder. For comparison, Fig. 25 presents the concentrations of chemical elements found at the sleeve, input window, collector, and the particles. For the sleeve, averaging was carried out over 13 measurements, for the input window - over 7 measurements, for the collector - over 9 measurements, and for the particles - over 21 measurements. Fig. 26 shows the concentrations of chemical elements averaged

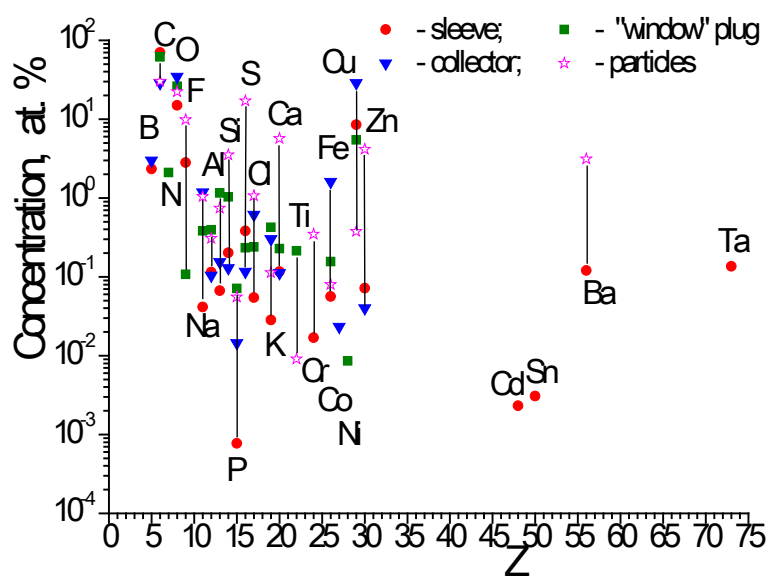

Fig. 25. A comparison of the element concentrations found at the sleeve, "window" plug, collector and the particles. 


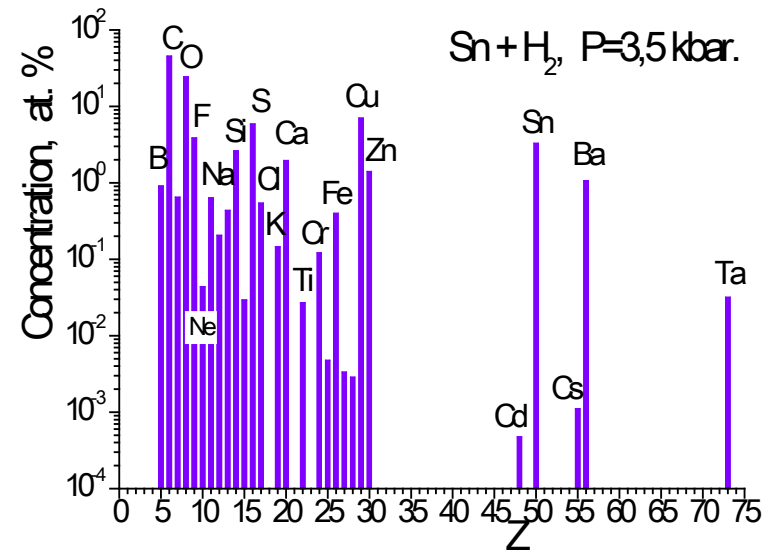

Fig. 26. The concentrations of chemical elements $(63$ measurements).

over all 63 measurements of synthesized solid-state structures.

\section{THE EXPERIMENT WITH PALLADIUM IN HELIUM}

The latest experiment in the series was the experiment with a palladium cylinder placed in condensed helium (He, Tab. 1) [22-23]. The chamber was filled with helium to a pressure of 2.4 kbar. The irradiation was carried out using a tungsten convector with the thickness $1 \mathrm{~mm}$ and an Al-absorber with the thickness $25 \mathrm{~mm}$. The exposure time was 96 hours. In the process of irradiation, the pressure in the chamber did not fall, and even grew somewhat. When the chamber was opened after irradiation, 13 dark-colored particles up to 1 $\mathrm{mm}$ fell out of it. The entrance window, made of beryllium bronze, was covered with a thick visible layer of green-and-yellow color. The thread of the entrance window was filled with small particles balls of about 2 microns in size (Fig. 27). Fig. 28 shows the element concentrations in these balls, averaged over 4 measurements. Dark spots were found at the entire lateral surface of the palladium cylinder. Fig. 29 shows SEM images of these spots. Fig. 30 indicates the element concentrations at

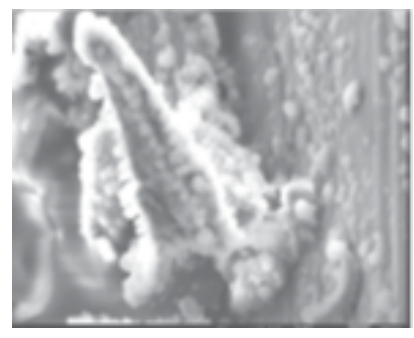

$a$

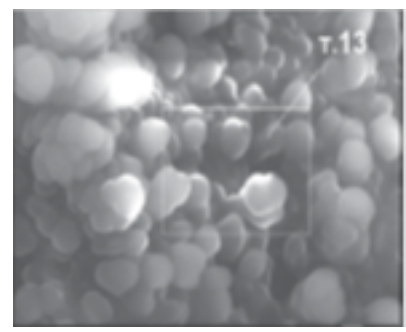

b
Fig. 27. The images showing structures in the threaded grooves: a) $(65 \mu \mathrm{m})$; b) $(14 \mu \mathrm{m})$.

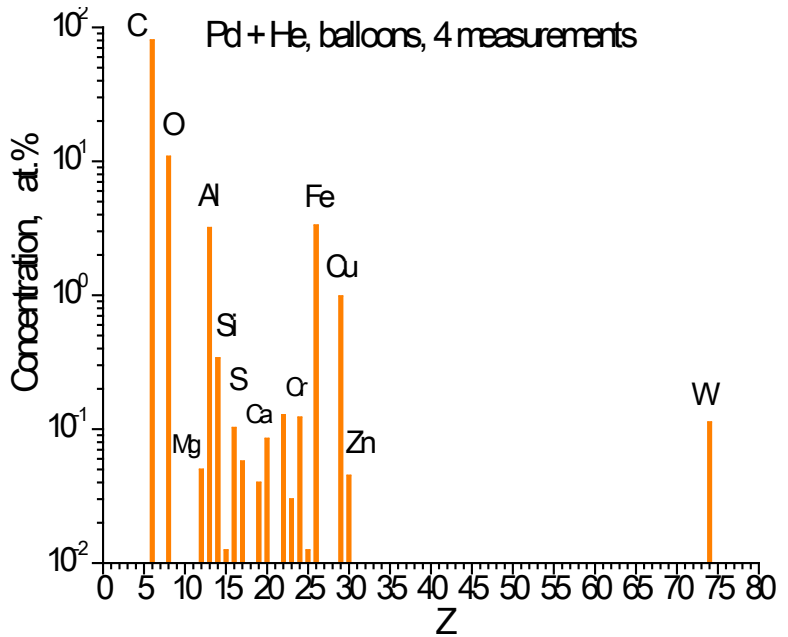

Fig. 28. The concentrations of chemical elements for the balloons.

these spots, averaged over 5 measurements. At these spots, besides carbon and oxygen, a high content of nitrogen, iron, and zinc was found. The total, averaged over 15 measurements concentrations of chemical elements at the surfaces of the palladium cylinder are presented in Fig. 31.

Studies of the chemical compositions of the synthesized structures on the surfaces of the entrance window (21 measurements), copper collector (3 measurements) and copper sleeve (16 measurements), as well as microparticles (13 measurements), showed the presence of "extraneous" chemical elements in them. Fig. 32 shows the total, averaged over 53 measurements concentrations of chemical elements for these chamber parts. A feature of this experiment with helium is the registration at the sleeve and at the particles of inert gases: neon and argon.

Fig. 33 shows the averaged over 68 measurements, including the surface of the $\mathrm{Pd}$ cylinder, concentrations of chemical elements measured in the experiment with helium. For comparison, Fig. 34 shows the concentrations of chemical elements averaged over 28 measurements and obtained in two experiments with pure helium at the pressure 1.1

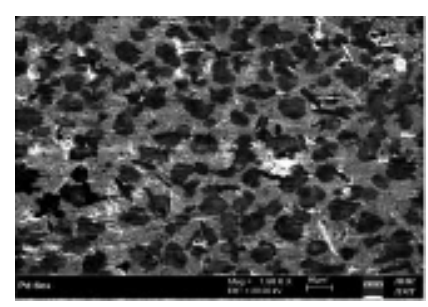

a

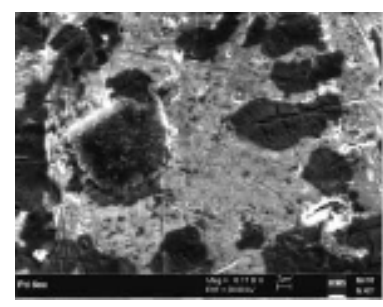

$b$
Fig. 29. A SEM mage of the side surface of the Pd cylinder littered with black spots: a) (150 um); b) (50 um). 


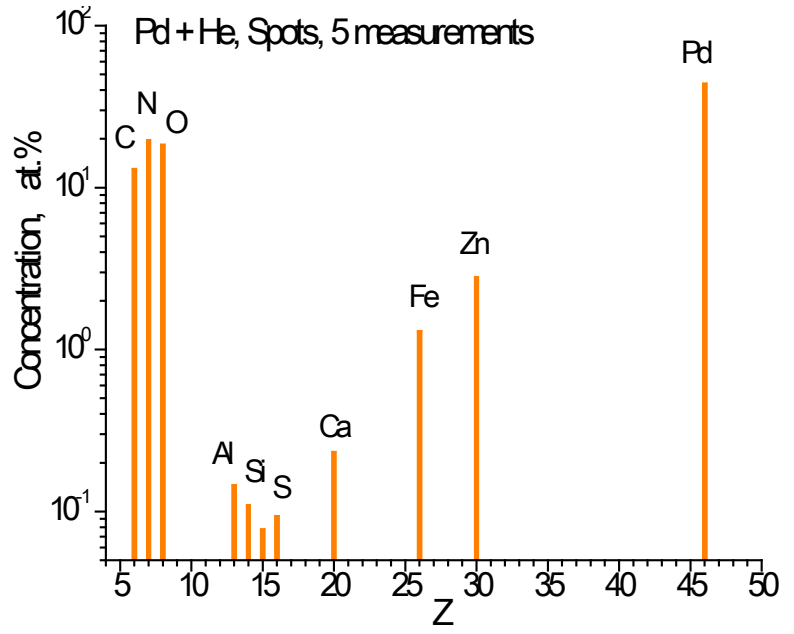

Fig. 30. The concentrations of chemical elements for the black spots.

and 3.05 kbar [39]. Irradiation was carried out for 28 hours each experiment, and the electron current was $(1.0-1.5) \cdot 10^{14} \mathrm{~s}^{-1}$. The electron beam energy was $10 \mathrm{MeV}$.

To complete the picture in Fig. 35, we present the general result on the irradiation by braking gamma quanta during 43 to 72 hours at the maximum energy $10 \mathrm{MeV}$ in condensed xenon $\left({ }_{54} \mathrm{Xe}\right)$ in three experiments [32-37, 39]. The figure shows the concentrations of the synthesized chemical elements averaged in these experiments at xenon pressures of 250, 270 and 550 bar. Averaging was performed for 289 measurements. It should be especially noted that due to the xenon irradiation, such radioactive elements as technetium $\left({ }_{43} \mathrm{Tc}\right)$ and actinium $\left({ }_{89} \mathrm{Ac}\right)$ (francium $\left({ }_{87} \mathrm{Fr}\right)$ is the daughter product of actinium) were synthesized. Their appearance can be explained neither by pollution nor by secondary processes. It should also be noted that as a result of long-term

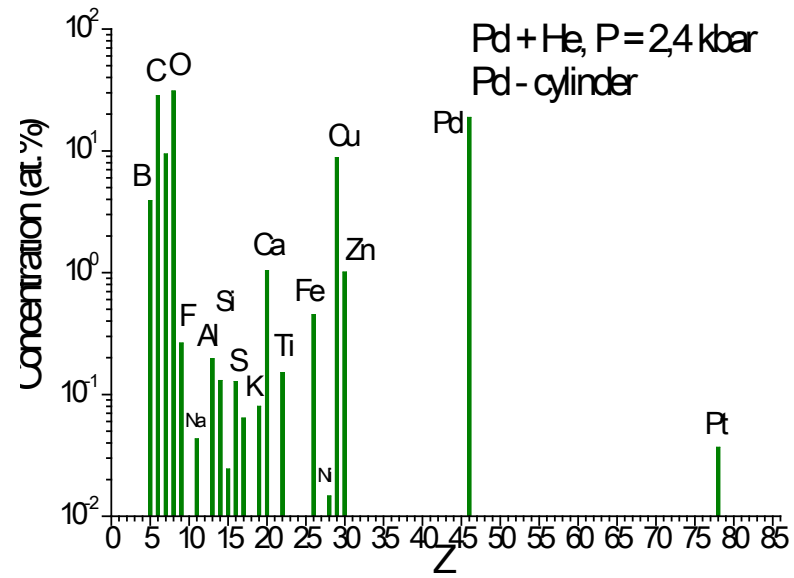

Fig. 31. The concentrations of chemical elements (15 measurements).

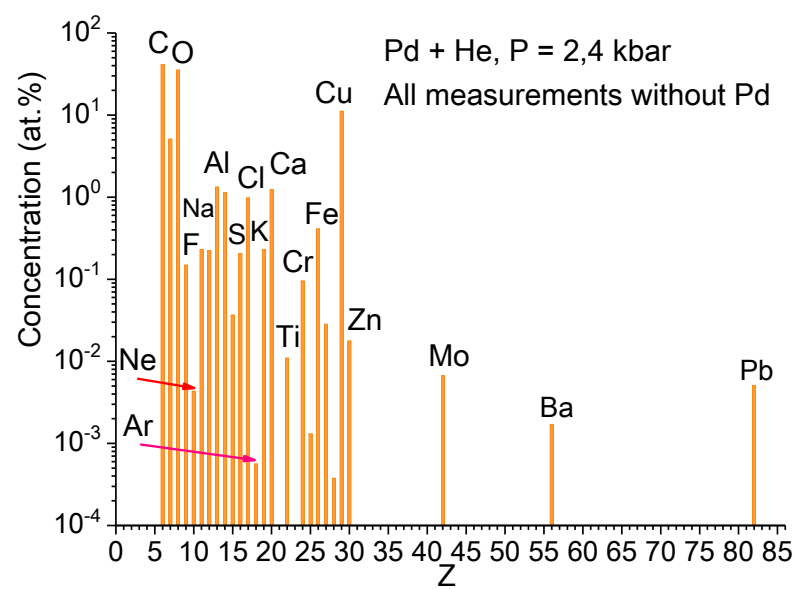

Fig. 32. The concentrations of chemical elements (53 measurements).

exposure to the braking gamma quanta of condensed xenon, "almost all elements" of the Periodic Table were synthesized here.

\section{DISCUSSION OF THE EXPERIMENTAL RESULTS}

First of all, it should be emphasized that, despite the striking results obtained in our numerous experiments and the interest of the scientific community, they were not reproduced at other scientific centers. Therefore, we are forced to compare the results of different experiments on the basis of our experimental data solely.

1. In all experiments with condensed gases, without exception, after the end of the irradiation, newly formed objects were found in the reaction chambers: microparticles ranging in size from $0.5 \mu \mathrm{m}$ to $1 \mathrm{~mm}$ and anomalous solid-state structures at the parts of the reaction chambers and at the surface of the palladium. Since the

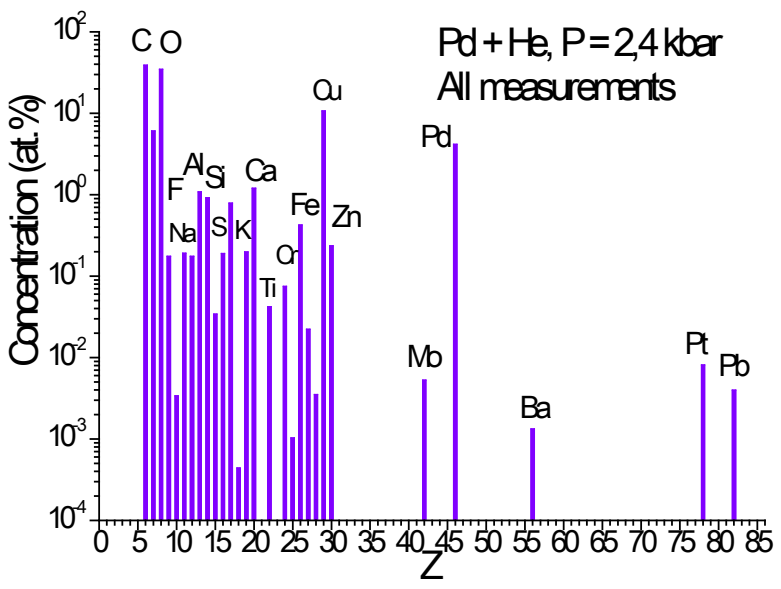

Fig. 33. The concentrations of chemical elements 168 measurements). 


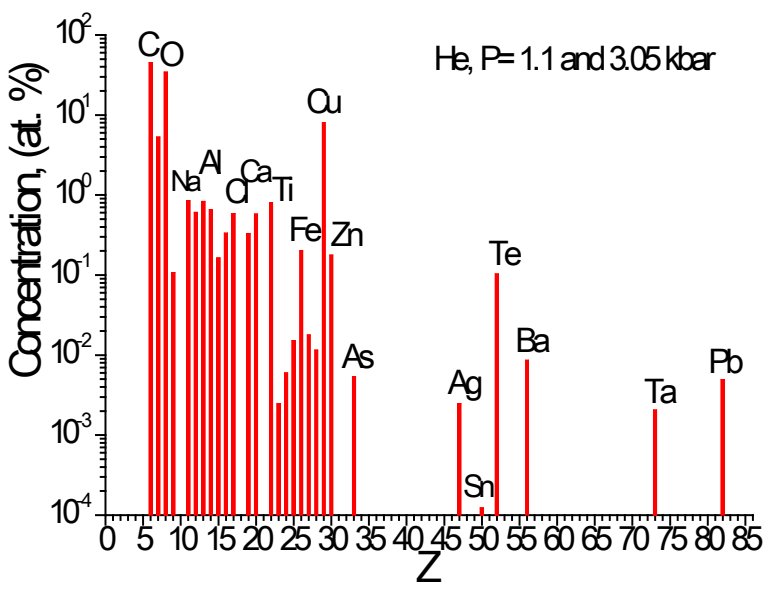

Fig. 34. The concentrations of elements for two experiments with $\mathrm{He}(28$ measurements).

structures formed contain a large number of "extraneous" chemical elements, it should be assumed that the structures and chemical elements were synthesized at the surfaces of the palladium cylinders and at the surfaces of the parts of the reaction chamber.

2. Studies performed by scanning electron microscopy, found significant changes in the surfaces of the irradiated Pd-cylinders. Smooth surfaces of the Pd-cylinders were transformed into inhomogeneous surfaces consisting of separate clusters with lots of cracks and spots. We interpret irregularities, cracks and ruptures which appear at the surface of the Pd-cylinders as radiation damage and microexplosions of the near-surface layer produced by nuclear reactions.

3. Measurements carried out using x-ray microprobe analysis showed that the surfaces of the Pd-cylinders, solid structures and microparticles contain chemical elements which were absent

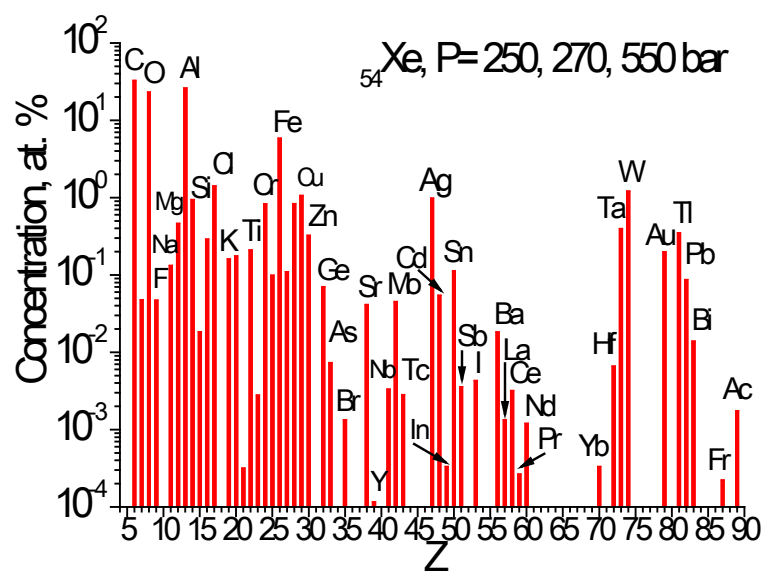

Fig. 35. The concentrations of chemical elements for three experiments with Xe (289 measurements). in appreciable quantities in the volumes of the reaction chambers before they were irradiated.

4. The range of the synthesized elements extends from carbon to lead. A characteristic feature for all of the obtained concentrations of chemical elements is the constant presence of the group with practically all light elements having the nuclear charge $6 \leq Z \leq 30$, from carbon to zinc. The maximum yield in the reactions is as follows: carbon and oxygen. Light elements up to carbon (in some cases, boron) are not recorded by x-ray microprobe analysis.

5. In addition to the group of light elements in the reaction products, there are always representatives from the group of elements with nuclear charge $\mathrm{Z}$ from 30 to 70 and there are representatives from the group of heavy elements with $Z$ greater than 70 . Almost always lead is present in the set of synthesized elements.

6. Taking into account the entire set of data obtained by the XRMPA method, it can be argued that in each individual experiment on the irradiation of gamma-quanta of palladium in condensed gases there is no significant difference in the distribution of chemical elements for the parts of the reaction chamber: the input window, sleeve, collector, manganin foil, and particles.

7. The most impressive experiments are the experiments with irradiation of palladium in a condensed deuterium atmosphere. In these experiments such elements as titanium ( $\left.{ }_{22} \mathrm{Ti}\right)$, silver $\left({ }_{47} \mathrm{Ag}\right)$ and lead $\left({ }_{82} \mathrm{~Pb}\right)$, were synthesized in macroquantity. The isotopic composition of lead in the range of measurement errors corresponds to the natural ratio of isotopes.

8. In the experiment with condensed helium such inert gases as neon and argon were recorded at the sleeve and at the particles. These elements do not form chemical compounds, so they could be synthesized and stored only inside and in the surface layers of the sleeves and particles.

9. In the experiments with condensed hydrogen and deuterium, radioactive elements were registered: protactinium $\left({ }_{91} \mathrm{~Pa}\right)$ and, possibly, curium $\left({ }_{96} \mathrm{Cm}\right)$ [42]. With a high degree of probability, these chemical elements were synthesized directly as a result of nuclear reactions.

10. The distributions of the synthesized chemical elements in the experiments with palladium 
and tin in condensed hydrogen differ little in character from each other (Fig. 22 and Fig. 26).

11. The distributions of synthesized chemical elements in the experiments on the irradiation of high-pressure chambers filled by condensed gases, with and without palladium, have a similar character [39].

A trivial explanation for the appearance of all "extraneous" chemical elements registered in experiments is their uncontrolled introduction into the internal volume of the reaction chambers during the process of filling the chambers with condensed gases. However, in addition to the fact that special measures were taken to eliminate the importation of "extraneous" chemical elements, special, "background" experiments were carried out to test this assumption: a) after several procedures for filling the reaction chamber with deuterium and evacuating it, the chamber was opened without irradiation; b) in the following experiment, the Pdsample was held in the chamber for $10^{5} s$ without irradiation at a deuterium pressure of $20 \mathrm{kbar}$; c) separately, irradiation was carried out at an electron energy of $10 \mathrm{MeV}$ for an empty chamber with all internal sleeves and collectors. The chamber between the exposures was constantly pumped out to the pressure $10^{-4} \mathrm{~Pa}$. The exposure time was $2 \cdot 10^{5} \mathrm{~s}$, for the average electron beam current $1.2 \cdot 10^{14} \mathrm{~s}^{-1}$; d) in another experiment, a chamber filled with deuterium at the pressure 60 bar with a palladium cylinder of $\varnothing 4.9 \times 8 \mathrm{~mm}^{3}$ in size was irradiated for $1.3 \cdot 10^{5} \mathrm{~s}$, with an average electron beam current of $1.1 \cdot 10^{14} \mathrm{~s}^{-1}$. Palladium was $99.997 \%$ pure. This experiment was aimed at the synthesis of chemical elements under reduced pressure of deuterium, which is compared to other experiments where the pressure of deuterium was 1.2 and 3 kbar [1-3, 7-10]. In all cases, the studies of the internal sleeves, collectors and the surface of the palladium cylinder made by SEM and XRMPA showed the absence of new synthesized structures and different elemental compositions in them.

Consequently, the appearance of "extraneous" elements in the internal volume of the reaction chambers, with a high degree of probability, is determined by non-nuclear interaction of gamma radiation in the atmosphere of condensed gases and with metal atoms surrounding the gas [43]. The interaction of gamma quanta with an energy up to $10 \mathrm{MeV}$ with a substance is characterized by: the photoelectric effect, the Compton effect, and the production of electron-positron pairs. All three effects lead to the formation of electrons and positrons with the energies $<10 \mathrm{MeV}$ which ionize the gas atoms and atoms of the materials surrounding the gas. Thus, a dense plasma with a high electron temperature is created in the irradiated volume. Consequently, the production of "extraneous" elements in the chamber is associated with the creation in its volume of a non-equilibrium dense plasma.

There are two nontrivial possibilities for the appearance of chemical elements. One of them is connected with the hypothesis of "plasma diffusion" of already existing impurity elements from the depth of materials surrounding the gas to the interface between two media: solid state and gas. In this case, the density of atoms in the gas must be comparable with the density of the solid. The second possibility is associated with the hypothesis of the emergence in dense plasma of conditions for the multinuclear fusion of several atomic nuclei into a common compound with its subsequent multinuclear fission into other fragment nuclei [43], i.e. implementation of low-energy nuclear reactions.

Indeed, strictly speaking, trace amounts of practically all elements, including radioactive elements, can be found in all metal alloys. Therefore, if there were a mechanism of "plasma diffusion" of impurity chemical elements from the depth of materials onto their surface with the obligatory presence of condensed gases, then this could somehow explain the appearance of "extraneous" elements, though in nano- and micro-quantities. But such a mechanism is unknown.

The introduction stated that one of the motivations in the formulation of the experiments discussed here was the implementation of cold fusion reactions for a palladium-deuterium pair. It is noteworthy that the most impressive experiments are experiments, just with the irradiation of palladium in a condensed deuterium atmosphere. In these experiments, such chemical elements as titanium, silver and lead were synthesized in macroquantities. From scientific literature it is known that cold nuclear fusion reactions are accompanied by transmutation reactions - the transformation of some chemical elements into others. Consequently, in our experiments with a palladium-deuterium 
pair, gamma-stimulated reactions of the cold fusion produce the energy necessary for transmutation reactions. In the experiments using other gases: hydrogen and helium, and in the experiments with pure gases, transmutation reactions occur directly. As was already mentioned, the intensity of cold fusion reactions increases with increasing number of deuterium atoms per palladium atom. "It is curious that nanoclusters of 6-7 nm size are formed near the metal surfaces, simply as a result of heating the sample to a temperature of $300-400^{\circ} \mathrm{C}$ ! Such nanoclusters levitate over a metal surface [44]! If cold fusion reactions occur in the volume of nanoclusters formed by any method, then due to the bombardment of metal surface by the reaction products, the metal surface is locally heated, and both additional local defects and new nanoclusters are produced on this surface. The "hot" defects and nanoclusters which emerge can become centers for the formation of solid structures and for the synthesis of "extraneous" chemical elements in low-energy nuclear transmutation reactions." $[45$, c. 128].It seems that we register such processes in our experiments.

\section{CONCLUSION}

This article provides an overview of eight years of experimental work on the synthesis of chemical elements from the gas phase of deuterium, hydrogen and helium in the presence of metallic palladium during long-term $\gamma$-irradiation of gases under high pressure. Numerous data have been obtained on the synthesis of for a wide range of chemical elements from carbon to lead. Preliminary hypotheses are proposed for the synthesis of chemical elements under the experimental conditions.

Based on the assumptions made, it is necessary to conduct new experiments that can confirm or disaprove both the results obtained and the indicated hypotheses.

\section{REFERENCES}

1. Didyk AYu, Wiśniewski R. Nuclear reactions, induced by gamma quanta, in palladium saturated with deuterium surrounded by dense deuterium gas. Eur. Phys. Lett., 2012, 99:P.22001-P1-22001-P6.

2. Didyk AYu, Wiśniewski R. Chemical Composition and Structural Phase Changes of Novel Synthesized Structure and of Pd Sample under $\gamma$-Quanta Irradiation in Dense Deuterium Gas. Phys. Part. Nucl.
Lett., 2012, 9(8):615-631.

3. Didyk AYu, Wiśniewski R. Sintez novykh struktur $\mathrm{v}$ plotnom gazoobraznom deyterii $\mathrm{i}$ nasyshchennom deyteriem palladii pri yadernykh reaktsiyakh, initsiirovannykh $\quad \gamma$-kvantami [Synthesis of new structures in dense gaseous deuterium and in deuterium-saturated palladium during nuclear reactions initiated by $\gamma$-quanta]. Physics and chemistry of materials processing, 2012, 5:5-13 (in Russ.).

4. Belov AG. Microtron MT-25. Workshop on the use of microtrons in nuclear physics. Plovdiv. September 22-24.1992. A15-93-80, pp.12-19. Dubna, 1993.

5. Fleishmann $\mathrm{M}$, Pons $\mathrm{S}$, Hawkins $\mathrm{M}$. Electrochemically induced nuclear fusion of deuterium.J. Electroanal. Chem. 1989, 261:301-308.

6. Arata Y, Zhang Y-C. Characteristics of Compact and Practical "Solid Deuterium Nuclear Fusion Reactor". Proc. 10th Intern.Conference on Cold Fusion, 2003, Cambridge, Massachusetts, USA.

7. Didyk AYu, Wiśniewski R, WilczynskaKitowska T, Shilov VM. Changes in the Chemical Composition of Nuclear Reaction Products Irradiated with $10 \mathrm{MeV} \gamma$-Quanta in Deuterium Saturated Palladium. (1.2kbar). J. Surface Investigation. X-ray, Synchrotron and Neutron Techniques, 2014, 8(6):1100-1112.

8. Didyk AYu, Wiśniewski R. Nuclear reactions in deuterium-saturated palladium under irradiation by $10 \mathrm{MeV} \gamma$-quanta in dense molecular deuterium at $1.2 \mathrm{kbar}$ pressure. Eur. Phys. Lett., 2013, 103:42002-P1-42002-P6.

9. Didyk AYu, Wiśniewski R, Wilczynska-Kitowska T. Changes of surface structure and elemental composition of Pd rod and collector of nuclear reaction products irradiated with $10-\mathrm{MeV}$ $\gamma$-quanta in dense deuterium gas. Phys. Part. Nucl. Lett., 2013, 10(7):804-819.

10. Didyk AYu, Wiśniewski R, Wilczynska-Kitowska T. Changes of surface structure and elemental composition of components of deuterium highpressure chamber with $\mathrm{Pd}$ rod inside irradiated with $10-\mathrm{MeV} \gamma$-quanta in dense deuterium gas. Phys. Part. Nucl. Lett., 2013, 10(7):820-832.

11. Didyk AYu, Wiśniewski R. Nuclear reactions in deuterated palladium and rhenium irradiated by $\gamma$ quanta with a continuous spectrum at a threshold energy of $23 \mathrm{MeV}$ in dense deuterium gas. Phys. Part. Nucl. Lett., 2013, 10(4):381-392. 
12. Didyk AYu, Wiśniewski R. The Study of Changes in the Element Compositions of $\mathrm{Pd}$ and Re Specimens Irradiated in Dense Gaseous Deuterium by $\gamma$-Quanta with Boundary Energy up to $23 \mathrm{MeV}$. Journal of Physical Science and Application, 2013, 3(4):209-217.

13. Didyk AYu, Wiśniewski R. Izmeneniya poverkhnosti, ob'emnykh svoystv obraztsov vanadiya i nerzhaveyushchey stali, obluchennykh v plotnom gazoobraznom deyterii $\gamma$-kvantamy s porogovoy energiey $23 \mathrm{MeV}$ [Changes observed in the surfaces, bulk properties and chemical composition of vanadium and stainless steel specimens irradiated in dense gaseous deuterium by $\gamma$-quanta of threshold energy $23 \mathrm{MeV}$. Preprint JINR P15-2012-75, Dubna, 2012, 15 p (in Russ.).

14. Didyk AYu, Wiśniewski R. Results of irradiation of aluminum and a homogeneous alloy $\mathrm{YMn}_{2} \gamma$-quanta with energy of $23 \mathrm{MeV}$ in the atmosphere of molecular deuterium at a pressure of 2 kbar. Phys. Part. Nucl. Lett., 2014, 11, 2:169-179.

15. Didyk AYu, Wiśniewski R. Results from the irradiation of stainless steel and copper by 23 $\mathrm{MeV} \gamma$-quanta in the atmosphere of molecular deuterium at a pressure of 2 kbar. Particles and Nuclei Letters, 2014, 11(3):309-328.

16. Didyk AYu, Wiśniewski R. Structure and chemical composition changes of Pd rod and reaction product collector irradiated by $10 \mathrm{MeV}$ braking gamma quanta inside high pressure chamber filled with $2.5 \mathrm{kbar}$ molecular hydrogen. Phys. Part. Nucl. Lett., 2014,. 11(4):513-527.

17. Didyk AYu, Wiśniewski R. Synthesis of new structures on the surface of Pd rod and HHPC elements and their chemical composition in nuclear reactions induced by bremstrahlung $\gamma$ quanta with threshold energy of $10 \mathrm{MeV}$ in molecular hydrogen at a pressure of $0.5 \mathrm{kbar}$. Phys. Part. Nucl. Lett., 2015, 12(4):603-617.

18. Didyk AYu, Wiśniewski R. Chemical composition and structure of particles synthesized on the surface of HHPC in nuclear reactions induced by bremstrahlung $\gamma$ quanta with threshold energy of $10 \mathrm{MeV}$ in molecular hydrogen at a pressure of 0.5 kbar. Phys. Part. Nucl. Lett., 2015, 12(7):836-849.
19. Didyk AYu, Wiśniewski R. Yadernye reaktsii s sintezom mikrochastits $\mathrm{v}$ vodorode pri davlenii 3.5 kbar $\mathrm{v}$ prisutstvii olova pri obluchenii tormoznymi $\gamma$-kvantami s porogovoy energiey $10 \mathrm{MeV}$ Nuclear reactions with synthesis of microparticles in hydrogen at a pressure of 3.5 kbar in the presence of Tin under irradiation by braking $\gamma$-quanta with a threshold energy of 10 MeV]. Preprint JINR P15-2014-89, Dubna, 2014, 26 p (in Russ.).

20. Didyk AYu, Wiśniewski R. Yadernye reaktsii $\mathrm{s}$ sintezom mikrochastits $\mathrm{v}$ HHPC pri davlenii 3.5 kbar vodoroda $\mathrm{s}$ tsilindrom iz olova pod deystviem oblucheniya tormoznymi $\gamma$-kvantami s porogovoy energiey $10 \mathrm{Mev}$ [Nuclear reactions with synthesis of structures in HHPC with hydrogen at a pressure of $3.5 \mathrm{kbar}$ and a Tin rod under irradiation of braking $\gamma$-rays with a threshold energy of $10 \mathrm{MeV}$. Preprint JINR P152014-88, Dubna, 2014, 43 p (in Russ.).

21. Didyk AYu, Wiśniewski R, Wilczynska-Kitowska T, Ishakova LD. Sintez mikrochastits v plotnom vodorode pri davlenii $3.5 \mathrm{kbar}$ s olovyannym sterzhnem pod deystviem tormoznykh $\gamma$-kvantov s porogovoy energiey $10 \mathrm{MeV}$ [Synthesis of microparticles in dense hydrogen at a pressure of $3.5 \mathrm{kbar}$ with a Tin rod under irradiation with braking $\gamma$-rays of a threshold energy of $10 \mathrm{MeV}$ ]. Preprint JINR P15-2014-104, Dubna, 2014, 23 p (in Russ.).

22. Didyk AYu, Wiśniewski R, Semin VA. Sintez mikrochastits $\mathrm{v}$ gelii pri davlenii 2.4 kbar $\mathrm{s}$ palladiem pri obluchenii tormoznami $\gamma$-kvantami s maksimalnoy energiey $10 \mathrm{MeV}$ (chst' 1) [The synthesis of microparticles in helium at a pressure of $2.4 \mathrm{kbar}$ with a palladium rod inside HeHPC under Irradiation by braking $\gamma$-rays with a maximum energy of $10 \mathrm{MeV}$. (part 1)]. Preprint JINR P15-2015-33, Dubna, 2015, 37 p (in Russ.).

23. Didyk AYu, Wiśniewski R, Semin VA. Issledovanie protsessov obrazovaniya novykh struktur i elementov v gelii pri davlenii 2.4 kbar s palladiem pri vozdeystvii tormoznykh $\gamma$-kvantov s maksimalnoy energiey $10 \mathrm{MeV}$ (chast' 2) [A study of the formation of new structures and elements in HeHPC with palladium inside at a pressure of $2.4 \mathrm{kbar}$ under the influence of braking $\gamma$-rays with a maximum energy of $10 \mathrm{MeV}$ (part 2)]. 
Preprint JINR P15-2015-34, Dubna, 2015, 34 p (in Russ.).

24. Didyk AYu, Wiśniewski R. Synthesis of microobjectsin 1 kbar hydrogen induced by 10 $\mathrm{MeV}$ bremsstrahlung $\gamma$ quanta on inner surfaces of components of a high pressure chamber (Part 1). Phys. Part. Nucl. Lett., 2015, 12(1):125-144.

25. Didyk AYu, Wiśniewski R. Synthesis of microparticles in $1 \mathrm{kbar}$ hydrogen induced by $10 \mathrm{MeV}$ bremsstrahlung $\gamma$ quanta in a reaction chamber (Part 2). Phys. Part. Nucl. Lett., 2015, 12(1):145-165.

26. Didyk AYu, Wiśniewski R. Sintez novykh struktur, obrazovannykh $\mathrm{v}$ rezul'tate yadernykh reactsiy $\mathrm{v}$ HHPC s davleniem vodoroda 3.4 kbar pri obluchenii tormoznymi $\gamma$-kvantami s porogovoy enrgiey $10 \mathrm{MeV}$ [New structures synthesized by nuclear reactions in HHPC with a hydrogen pressure of $3.4 \mathrm{kbar}$ under irradiation by braking $\gamma$-rays with a threshold energy of 10 MeV]. Preprint JINR P15-2015-79, Dubna, 2015, $27 \mathrm{p}$ (in Russ.).

27. Didyk AYu, Wiśniewski R, Mishinsky GV, Semin VA, Wilczynska-Kitowska T. Sintez tverdotelnukh struktur i khimicheskikh elementov pri obluchenii tormoznymi $\gamma$-kvantami c $\mathrm{E}_{\max }=10$ $\mathrm{MeV}$ kondensirovannogo deyteriya davleniem 2.2 kbar [Synthesis of solid-state structures and chemical elements under irradiation by bremsstrahlung $\gamma$ rays with a maximum energy of $10 \mathrm{MeV}$ in condensed deuterium at a pressure of 2.2 kbar]. Preprint JINR P15-2018-3, Dubna, 2018, 27 p (in Russ.).

28. Didyk AYu, Wiśniewski R., Wilczynska-Kitowska T. The carbon-based structures synthesized through nuclear reactions in helium at $1.1 \mathrm{kbar}$ pressure under irradiation with braking $\gamma$-rays of $10 \mathrm{MeV}$ threshold energy. Eur. Phys. Lett., 2015, 109:22001-P.1-22001-P.6.

29. Didyk AYu, Wiśniewski R. Properties of carbon-based structures synthesized in nuclear reactions induced by bremsstrahlung $\gamma$ quanta with threshold energy of $10 \mathrm{MeV}$ at helium pressure of 1.1 kbar. Phys. Part. Nucl. Lett., 2016, 13(4):492-503.

30. Didyk AYu, Wiśniewski R. Yadernye reaktsii, sintez khimicheskikh elementov i novykh struktur v plotnom gelii pri davlenii $1.1 \mathrm{kbar}$ pod deystviem oblucheniya tormoznymi $\gamma$-kvantami s porogovoy energiey $10 \mathrm{MeV}$ [Nuclear reactions, synthesis of chemical elements and new structures in dense helium at $1.1 \mathrm{kbar}$ pressure under irradiation with braking $\gamma$-quanta with a threshold energy of $10 \mathrm{MeV}$ ]. Preprint JINR P152014-50, Dubna, 2014, 40 p (in Russ.).

31. Didyk AYu, Wiśniewski R. Sintez novykh struktur i obrazovanie khimicheskikh elemetov $\mathrm{v}$ plotnom gelii pri davlenii $3.05 \mathrm{kbar}$ pri obluchenii tormoznymi $\gamma$-kvantami s porogovoy energiey $10 \mathrm{MeV}$ [Synthesis of new structures and formation of chemical elements in dense helium at a pressure of $3.05 \mathrm{kbar}$ under irradiation of braking $\gamma$-rays with a threshold energy of 10 MeV]. Preprint JINR P15-2014-87, Dubna, 2014, $23 \mathrm{p}$ (in Russ.).

32. Didyk AYu, Gulbekian GG, Mishynsky GV. SEM i RMPA-issledovaniya sintezirovannykh chastits i ob'ektov pri obluchenii plotnogo ksenona (270 atm) tormoznymi $\gamma$-kvantami s maksimalnoy energiey 10 $\mathrm{MeV}$ [SEM and RMPA research of synthesized particles and objects in dense xenon (270 bar) irradiated by braking $\gamma$-rays with a maximum energy of $10 \mathrm{MeV}$. Preprint JINR P15-2015-71, Dubna, 2015, 38 p (in Russ.).

33. Didyk AYu, Gulbekian GG, Mishynsky GV. Issledovanie izmeneniy elementnogo sostava $\mathrm{i}$ struktury poverkhnostey pri obluchenii plotnogo ksenona (270 atm) tormoznymi $\gamma$-kvantami s maksimalnoy energiey $10 \mathrm{MeV}$ [A study of the element composition and surface structure changes during irradiation of dense xenon (270 atm) by braking $\gamma$-rays with a maximum energy of $10 \mathrm{MeV}$. Preprint JINR P15-2015-72, Dubna, 2015, 32 p (in Russ.).

34. Didyk AYu, Gulbekian GG, Mishinsky GV. Anomalii na vnutrennikh poverkhnostyakh kamery vysokogo davleniya ksenona XeHPC (250 bar) s obrazovaniem mikrochastits slozhnogo sostava pri obluchenii tormoznym izlucheniem s porogovoy energiey $10 \mathrm{MeV}$ [Anomalies on the inner surfaces of the xenon high-pressure chamber XeHPC (250 Bar) with the synthesis of microparticles of complex composition under irradiation with bremsstrahlung threshold energy of $10 \mathrm{MeV}$. Preprint JINR P15-2016-1, Dubna, 2016, 47 p (in Russ.).

35. Didyk AYu, Gulbekian HS, Mishinsky GV, Sabelnikov AV. Sintez mikrochastits slozhnogo 
coctava $\mathrm{v}$ kamere vysokogo davleniya ksenona (550 bar) pti obluchenii tormoznym izlucheniem s maksimal'noy energiey $10 \mathrm{MeV}$ [The synthesis of micro particles of complex composition in the chamber high-pressure xenon (550 bar) when irradiated by bremsstrahlung with maximum energy of $10 \mathrm{MeV}$. Preprint JINR P15-2016-19, Dubna, 2016, 49 p (in Russ.).

36. Didyk AYu, Gulbekian GG, Mishinsky GV, Wiśniewski R. A study of changes of the element composition and structure of surfaces under irradiation of dense xenon gas (270 bar) by $\gamma$-rays with maximum energy of $10 \mathrm{MeV}$. JPS A, 2016, 6(2):18-28.

37. Didyk AYu. Yadernye reaktsii sinteza i deleniya khimicheskikh elementov i obrazovaniye novykh struktur $\mathrm{v}$ plotnykh gazakh $\mathrm{H}_{2}, \mathrm{D}_{2} \mathrm{i}$ He pri obluchenii $10 \mathrm{Mev} \gamma$-kvantami [Nuclear reactions of fusion and fission chemical elements and the formation of new structures in dense gases $\mathrm{H}_{2}, \mathrm{D}_{2}$ and $\mathrm{He}$ at irradiation $10 \mathrm{MeV}$-tion of $\gamma$-quanta]. Physics and chemistry of materials processing, 2015, 2:5-19.

38. Wiśniewski R, Didyk AYu. Synthesis of New Structures and Substances in Dense Gases H2, D2 and He under Irradiation by Braking $10 \mathrm{MeV}$ $\gamma$-rays in CuBe2 Pressure Chamber. JPSA, 2016, 6(4):13-21.

39. Wiśniewski R, Mishinsky GV, Gulbekian GG, Wilczyńska-Kitowska T, Semin VA. Sintez khimicheskikh elementovitverdotelnukh struktur pri obluchenii $\gamma$-kvantami kondensirovannykh gazov [Synthesis of chemical elements and solidstate structures under irradiation by $\gamma$-quanta in condensed gases]. Zhurnal Formiruyushchkbsya Napravleniy Nauki (ZhFNN), 2017, 17-18(5):6-15 (in Russ.). http://www.unconv-science.org/.

40. Berger MJ, Seltzer SM. Bremsstrahlung and Photoneutrons from Thick Tungsten and Tantalum Targets. Phys. Rev. C, 1970,2(2):621-631.

41. Kondev Ph, Tonchev A, Khristov Kh, Zhuchko V. The calculated bremsstrahlung spectrum. Nucl. Instr. Meth. B71, 1992, 126.

42. Didyk AYu, Konarsky P, Sabelnikov AV, Wiśniewski R. Obrazovanie Pa i Cm pri oblychenii palladievogo sterzhnya $\mathrm{v}$ DHPC, zapolnennoy molekulyarnym deyteriem pri davlenii $1.2 \mathrm{kbar}$, tormoznym izlucheniem s maksimalnoy energiey $10 \mathrm{MeV}[\mathrm{Pa}$ and $\mathrm{Cm}$ production under irradiation of palladium rod in the molecular deuterium at a pressure of $1.2 \mathrm{kbar}$ by braking radiation with a $10 \mathrm{MeV}$ maximum energy]. Preprint JINR P152015-78, Dubna, 2018, 39 p (in Russ.).

43. Mishinsky GV, Kuznetsov VD, Penkov FM. K voprosu o mekhanizme sinteza khimicheskikh elementov pri obluchenii kondensirovannykh gazov tormoznymi gamma-kvantami [To the question of mechanism of synthesis of chemical elements at irradiation of condensed gases by bremsstrahlung gamma quanta]. ZhFNN, 2017, 17-18(5):45-57 (in Russ.).

44. Nesvizhevsky VV, Voronin AYu, Lambrecht A,Reynaud S, Lychagin EV, Muzychka AYu, Strelkov AV. Observation of quantum levitation of nanoparticles by the method of ultracold neutrons. Crystallography, 2013, 58(5):730-736.

45. Mishinsky GV. Theory of cold fusion reactions. Radioelectronics. Nanosystems. Information Technologies (RENSIT), 2019,11(2):125-142. DOI: 10.17725/ rensit.2019.11.125. 